Apidologie, 1975, 6 (1), 59-90.

\title{
UNTERSUCHUNGEN AN HANDELSHONIGEN MIT SPEZIELLER BERÜCKSICHTIGUNG DES ZUCKERSPEKTRUMS
}

\author{
Analyse de miels commerciaux \\ considérant spécialement le spectre des sucres
}

K. ZÜRCHER, A. MAURIZIO und H. HADORN

Basel und Liebefeld, Schweiz

SUMMARY

TRADE HONEY ANALYSIS WITH SPECIAL REFERENCE TO SUGAR SPECTRUM

In this study 54 honeys marketed in Switzerland were examined by chemical, physicaand microscopic analysis. The main point of interest was the sugar spectrum, determined by gas chromatography, and its relation to the provenance of the honeys from various flows. Other characteristics determined were : colour, granulation, $\mathrm{pH}$-value, degree of acidity, enzyme activity and the content of water and HMF. The results are shown in Tables 3 and 4 and are discussed in the text.

\section{ZUSAMMENFASSUNG}

Die vorliegende Arbeit umfasst die chemische, physikalische und mikroskopische Untersuchung von 54 in der Schweiz angebotenen Handelshonigen. Im Vordergrund des Interesses stehen das gaschromatographisch bestimmte Zuckerspektrum und die Zusammenhänge zwischen diesem und der trachtmässigen Herkunft der untersuchten Honige. Ausserdem wurden geprüft : Farbe, Kristallisationsform, pH-Wert, Säuregrad, Enzymaktivität, Wasserund HMF-Gehalt. Die Ergebnisse der Untersuchung sind in den Tabellen 3 und 4 zusammengestellt und werden im Text diskutiert.

\section{1. - EINFÜHRUNG}

Vor einiger Zeit veranstaltete eine schweizerische Grosshandelsfirma eine Aktion unter dem Motto “ Mit Honig um die Welt ». Es wurden über 
50 Honige verschiedener Provenienz und Sorten angeboten. Da sich das Laboratorium der COOP Schweiz seit mehreren Jahren mit Honiganalysen beschäftigt und verschiedene neue Analysenmethoden ausgearbeitet hat, bot sich hier die Gelegenheit, diese Methoden an einer grösseren Zahl von Honigen anzuwenden und gleichzeitig einen Ueberblick zu gewinnen über die Variabilität der Zusammensetzung und über die Qualität der auf dem Schweizermarkt angebotenen Honige.

Das Interesse galt vor allem dem gaschromatographisch bestimmten Zuckerspektrum und den Zusammenhängen zwischen Zucker- und Pollenspektrum der Honige. Die chemischen und physikalischen Analysen wurden deshalb durch eine mikroskopische Untersuchung ergänzt. Neben dem Zuckerspektrum und dem Pollenbild wurden geprïft : Farbe, Konsistenz, pH-Wert, Säuregrad, Wassergehalt, Enzymaktivität und der Gehalt an Hydroximethylfurfural.

\section{2. - MATERIAL UND METHODIK}

Das Untersuchungsmaterial umfasst 54 Honige, die in Originalpackungen im Detailhandel gekauft wurden. Ueber das Alter und die Behandlung der Honige vor dem Abfüllen war nichts näheres bekannt; über die geographische und trachtmässige Herkunft lagen nur die auf den Etiketten genannten Angaben vor.

Zur Beschreibung der Konsistenz (Kristallisationsform) wurde die von White u. Mitarb. (1962) aufgestellte Skala benutzt. Da sie nicht für alle untersuchten Honige passte, wurden dazu einige Ergänzungen gemacht (Tab. 1). Unter den vollständig weich durchkristallisierten Honigen (Ziffer 8) fanden sich solche die fest waren, andere dagegen waren hochviskos, was mit der heutigen technologischen Behandlungsweise des Honigs im Grossbetrieb in Zusammenhang stehen dürfte. In Tabelle 3 ist daher unter Ziffer 8 jeweils angegeben, ob der weich durchkristallisierte Honig “ fest » oder « hochviskos » war.

ТАв. 1. - Bezeichnung des Kristallisationsgrades nach White und Mitarb. (1962)

TABL. 1. - Degré de cristallisation selon White et al. (1962)

\begin{tabular}{|c|c|c|}
\hline $\begin{array}{l}\text { Ziffer } \\
\text { Code }\end{array}$ & Aussehen & Aspect \\
\hline 0 & vollständig flüssig & entièrement liquide \\
\hline 1 & wenig vereinzelte Kristalle & quelques cristaux \\
\hline 2 & 1,5-3 $\mathrm{mm}$ hohe kristallisierte Bodenschicht & une couche cristallisée de $1,5-3 \mathrm{~mm}$ \\
\hline 3 & wenig Kristallklumpen & quelques grumeaux cristallités \\
\hline 4 & 6.12 mm hohe Bodenkristallschicht & couche cristallisée de $6-12 \mathrm{~mm}$ \\
\hline 5 & 1/4 der Honigschichthöhe kristallisiert. & $1 / 4$ cristallisé \\
\hline 6 & 1/2 der Honigschichthöhe kristallisiert. & $1 / 2$ cristallisé \\
\hline 7 & 3/4 der Honigschichthöhe kristallisiert. & $3 / 4$ cristallisé \\
\hline 8 & $\begin{array}{l}\text { vollkommen weich durchkristallisiert } \\
\text { (fest oder hochviskos) } \\
\text { An der Oberfläche evtl. eine dünne flüssige Schicht } \\
\text { (1-3 mm) }\end{array}$ & $\begin{array}{l}\text { masse molle, complètement cristallisée } \\
\text { (solide. ou visqueuse) } \\
\text { A la surface éventuellement une mince } \\
\text { couche liquide }\end{array}$ \\
\hline 9 & $\begin{array}{l}\text { vollkommen hart durchkristallisiert } \\
\text { thixotrop }\end{array}$ & $\begin{array}{l}\text { masse dure, complètement cristallisée } \\
\text { thixotrope }\end{array}$ \\
\hline
\end{tabular}


Die Farbe wurde nach der verkaufsertigen Packung beschrieben, da der Käufer den Honig nur nach dieser Farbe beurteilt. Wissenschaftlich genauer wäre es, den Honig zu schmelzen und die Farbe in der Durchsicht zu definieren, wie es von von Fellenberg (1946), Sechrist (1925) und andern Autoren beschrieben worden ist (s. Vorwohl 1975).

Durch Worte lassen sich Mischfarben nur mangelhaft beschreiben. Zur genauen Farbbeurteilung haben wir daher den Farbatlas von Munsell (1929) herangezogen. Aus diesem Atlas wurden 32 passende Farbplättchen entnommen. Je 8 dieser Plättchen wurden auf einem Kartonstreifen montiert, so dass jeweils oben der hellste, unten der dunkelste Farbton einer Reihe zu stehen kam. Die 4 Streifen enthielten die in Tabelle 2 angegebenen Farben. In der Schweiz sind die Farbplättchen zu beziehen von H. A. Sarasin, chemisch-technische Geräte, Basel, Aeschenvorstadt 37.

Nach dem Farbsystem von Munsell wird eine Farbe durch 3 Begriffe definiert : HUE (Farbton), VALUE (Farbwert, Helligkeit) und CHROMA (Sättigung, Farbtiefe).

TAB. 2. - Farbplättchen aus dem MUNSELL-Farbatlas für die Charakterisierung der Honigfarbe

TABL. 2. - Assortiment de plaques de couleur de l'atlas MUNSEIL pour définir la couleur du miel

\begin{tabular}{|c|c|c|c|}
\hline $\begin{array}{c}\text { Blatt } 1 \\
\text { Farbe : graubraun } \\
\text { feuille } 1 \\
\text { couleur : gris-brun }\end{array}$ & $\begin{array}{c}\text { Blatt } 2 \\
\text { Farbe : braungelb } \\
\text { feuille } 2 \\
\text { couleur : brun-jaune }\end{array}$ & $\begin{array}{c}\text { Blatt } 3 \\
\text { Farbe : hell bis dunkel } \\
\text { rotbraun } \\
\text { feuille } 3 \\
\text { couleur : de brun-rouge clair } \\
\text { à foncé }\end{array}$ & $\begin{array}{c}\text { Blatt } 4 \\
\text { Farbe : gelbgriün bis } \\
\text { dunkelbraun } \\
\text { feuille } 4 \\
\text { couleur : jaune-vert } \\
\text { à brun foncé }\end{array}$ \\
\hline $\begin{array}{c}2,5 \mathrm{Y} \\
9 / 4\end{array}$ & $\begin{array}{c}10 \mathrm{YR} \\
8 / 6\end{array}$ & $\begin{array}{c}7,5 \text { YR } \\
7 / 8\end{array}$ & $\begin{array}{c}2,5 \mathrm{Y} \\
8,5 / 6\end{array}$ \\
\hline $\begin{array}{l}2,5 \mathrm{Y} \\
8,5 / 4\end{array}$ & $\begin{array}{c}10 \underset{7 / 6}{\mathrm{YR}} \\
\text {. }\end{array}$ & $\underset{6 / 8}{7,5 \text { YR }}$ & $\begin{array}{c}2,5 \mathrm{Y} \\
8 / 8\end{array}$ \\
\hline $\begin{array}{c}2,5 \mathrm{Y} \\
8 / 4\end{array}$ & $10 \underset{6 / 6}{\mathrm{YR}}$ & $\underset{5 / 8}{7,5 \text { YR }}$ & $\begin{array}{c}2,5 \mathrm{Y} \\
7 / 10\end{array}$ \\
\hline $\begin{array}{c}2,5 \mathrm{Y} \\
7 / 4\end{array}$ & $\begin{array}{c}10 \underset{5 / 6}{\mathrm{YR}} \\
0\end{array}$ & $\begin{array}{c}2,5 \mathrm{YR} \\
6 / 12\end{array}$ & $10 \underset{7 / 8}{\mathrm{YR}}$ \\
\hline $\begin{array}{c}2,5 \mathrm{Y} \\
6 / 4\end{array}$ & $10 \underset{4 / 6}{\mathrm{YR}}$ & $\begin{array}{c}2,5 \text { YR } \\
5 / 10\end{array}$ & $\underset{5 / 10}{7,5 \text { YR }}$ \\
\hline $\begin{array}{c}2,5 \mathrm{Y} \\
5 / 4\end{array}$ & $\underset{7 / 8}{2,5 \mathrm{Y}}$ & $\underset{4 / 8}{2,5}$ & $\underset{3 / 6}{2,5 \text { YR }}$ \\
\hline $\begin{array}{c}2,5 Y \\
4 / 4\end{array}$ & $\underset{6 / 8}{2,5 \mathrm{Y}}$ & $\underset{3 / 6}{2,5}$ YR & $\begin{array}{c}2,5 \mathrm{YR} \\
2 / 4\end{array}$ \\
\hline $\begin{array}{c}2,5 Y \\
3 / 4\end{array}$ & $\underset{5 / 8}{2,5 Y}$ & $\underset{2,5}{2,4}$ & $\begin{array}{c}2,5 \underset{2 / 2}{Y R} \\
\end{array}$ \\
\hline
\end{tabular}

Erläuterungen Zur Charakterisierung einer Farbe werden die Anfangsbuchstaben der englischen Farbbezeichnungen verwendet (z.B. YR $=$ Yellow-Red). Vor den Buchstaben steht eine Ziffer, welche den Farbton (HUE) bezeichnet. Unter den Buchstaben stehen 2 weitere, durch einen Schrägstrich getrennte Ziffern. Die erste bezieht sich auf die Helligkeit (value), die letztere auf die Sättigung oder Farbtiefe (CHroma).

Explications Pour définir une couleur on utilise la première lettre du nom anglais (par exemple YR = Yellow-Red). Avant les lettres il y a un chiffre, qui spécific la nuance (HUE). Sous les lettres il y a deux chiffres séparés par un trait oblique. Le premier indique la clarté (VALUE) et le deuxième l'intensité (CHROMA). 
Um die Farbe eines Honigs zu charakterisieren, sucht man das passende Farbplättchen, welches mit der Honigfarbe übereinstimmt oder ihr am nächsten kommt und drückt die bestimmte Farbe in einem Symbol aus (s. Tabelle 2). Farbtiefe und Farbnuance sind etwas abhängig von der Form und Grösse der Gläser. Die Farbe kann sich stark verändern, wenn flüssiger Honig kandiert.

Wassergehalt. Trockensubstanz und Wassergehalt wurden refraktometrisch bei $40{ }^{\circ} \mathrm{C}$ bestimmt (s. Schweiz. Lebensmittelbuch 1967).

pH-Wert und Säure wurden potentiometrisch nach der Methode von Hadorn und Zürcher (1963) bestimmt.

Hydroxymethylfurfural (HMF) wurde spektrophotometrisch nach der Methode von Winkler (1955) bestimmt (s. auch Hadorn und Kovacs 1960).

Saccharase-Aktivität. Die Saccharasezahl wurde nach der modifizierten polarimetrischen Methode bestimmt (Hadorn und Zürcher 1966). Die Saccharasezahl (SaZ) gibt an, wieviele Gramm Saccharose von dem in $100 \mathrm{~g}$ Honig enthaltenen Enzym in I Stunde, unter den beschriebenen Versuchsbedingungen gespalten werden.

Diastase-Aktivität. Die Diastasezahl wurde bestimmt nach der von uns ausgearbeiteten kinetischen Methode (Hadorn und Zürcher 1972). Die Diastasezahl (DZ) gibt an, wieviele Gramm Stärke von dem in $100 \mathrm{~g}$ Honig enthaltenen Enzym in 1 Stunde abgebaut werden.

Die Zucker wurden nach der von uns kürzlich beschriebenen gaschromatographischen Methode (Hadorn, Zürcher und Strack 1974) bestimmt. Die Zucker wurden zunächst in wasserfreiem Medium in ihre Silyläther übergeführt und an einer mit $3 \%$ OV-17 belegten Aeropack-Säule gaschromatographisch getrennt. Abbildung 1 zeigt das Gaschromatogramm einer Zucker-Modellmischung, Abbildung 2 dasjenige eines Waldhonigs. Aus den Peakflächen (Integrator-Impulsen) wurde die Verteilung der Zucker berechnet, so dass die Summe aller Zuckerarten $100 \%$ ergab. Korrekturfaktoren wurden nicht verwendet, da sich aus Modellmischungen ergab, dass diese Faktoren nur minim von 1 abweichen. Die Fruktosewerte dürften durchwegs etwas zu niedrig sein, weil bei unserer gaschromatographischen Bestimmungsmethode die Fruktose systematisch etwas zu niedrig, die Glukose etwas zu hoch gefunden wird (relativer Fehler ca $2-3 \%$ ).

Für alle Details der gaschromatographischen Methode und der Auswertung der mit ihr erzielten Resultate, sei auf die ausführliche Publikation hingewiesen (Hadorn, Zürcher und Strack 1974).

Die mikroskopische Untersuchung erfolgte in Anlehnung an die von der Internationalen Kommission für Bienenbotanik veröffentlichte Methode der Melissopalynologie (Int. Komm. Bienenbot. 1970). In der Regel wurden je Präparat 100 Pollenkörner und die dazugehörenden Honigtaubestandteile ausgezählt, in einigen Fällen wurden 200-300 Pollenkörner gezählt oder eine zusätzliche Auszählung (unter Vernachlässigung der Leitform) vorgenommen. Die Resultate der Pollenauszählung wurden wie üblich dargestellt als : Leitpollen $=$ über $45 \%$, Begleitpollen $=16-45 \%$, Einzelpollen $=1-15 \%$; für die Honigtaubestandteile wurden 5 Gruppen gebildet : keine $=0-0,1$, wenig $=0,1-0,5$, ziemlich viel $=0,5-1,0$, viel $=1,0-3,0$ und sehr viel $=$ über 3,0 Honigtaubestandteile auf 100 Pollenkörner.

\title{
ERGEBNISSE UND DISKUSSION
}

\author{
Anordnung der Resultate
}

Die Untersuchungsergebnisse der 54, Honige sind in den Tabellen 3 und 4 zusammengestellt. Tabelle 3 enthält die Angaben über die Bezeichnung, das Pollenspektrum und die äusseren Merkmale (Farbe, Kristallisationsform) der Proben; Tabelle 4 die Ergebnisse der physikalischen und chemischen Untersuchung (Wassergehalt, pH-Wert, Säure- und HMF-Gehalt, Saccharase- 
TAв. 3. - Bezeichnung, Pollenspektrum, Kristallisationsgrad und Farbtyp der untersuchten Honige ${ }^{1}$

TавL. 3. - Désignation, spectre pollinique, degré de cristallisation et couleur des miels analysês

\begin{tabular}{|c|c|c|c|c|c|}
\hline Nr. & $\begin{array}{c}\text { Bezeichnung } \\
\text { Designation }\end{array}$ & $\begin{array}{l}\text { Pollenspektrum } \\
\text { Spectre pollinique }\end{array}$ & $\begin{array}{l}\text { Honigtau- } \\
\text { anteil } \\
\text { Indicateurs } \\
\text { de miellat }\end{array}$ & $\begin{array}{l}\text { Kristallisa- } \\
\text { tionsgrad } \\
\text { Cristallisation }\end{array}$ & $\begin{array}{c}\text { Farbtyp } \\
\text { Couleur }\end{array}$ \\
\hline
\end{tabular}

1. Blütenhonige aus einseitiger Tracht - Miel de fleurs unifloraux

\begin{tabular}{|c|c|c|c|c|c|}
\hline 1 & $\begin{array}{l}\text { Heidehonig } \\
\text { Frankreich }\end{array}$ & $\begin{array}{l}\text { ** Calluna, Castanea } \\
\text { *** Erica cinerea, E. vagans, Trifolium } \\
\text { repens, Tr. pratense, Onobrychis, } \\
\text { Cruciferae, Hedera, Echium, Labia- } \\
\text { tae M. }\end{array}$ & kein & $\begin{array}{c}\text { thixotrop mit } \\
\text { groben } \\
\text { Kristallen }\end{array}$ & $\begin{array}{c}\text { Blatt } 4 \\
7,5 \text { YR } \\
5 / 10\end{array}$ \\
\hline $\begin{array}{c}2 \\
\vdots\end{array}$ & $\begin{array}{l}\text { Heidehonig } \\
\text { (abgefüllt } \\
\text { B.R.D.) }\end{array}$ & $\begin{array}{l}\text { ** } \text { Eucalyptus, Ulex } \\
\text { *** Calluna, Erica cinerea, E. vagans, } \\
\text { E. umbellata, Rosmarinus, Lavan- } \\
\text { dula, Citrus, Labiatae M., Cistus, } \\
\text { Castanea, Rhamnus, Onobrychis, } \\
\text { Asparagus, Olea, Hypecoum. }\end{array}$ & kein & thixotrop & $\begin{array}{c}\text { Blatt } 4 \\
2,5 \mathrm{Y} \\
2 / 4\end{array}$ \\
\hline 3 & $\begin{array}{l}\text { Blütenhonig } \\
\text { Tessin } \\
\text { Schweiz }\end{array}$ & ${ }_{* * *}^{*} \frac{\text { Castanea }}{\text { Tilia, Robinia, Rubus, Labiatae M., }}$ & kein & $\stackrel{8}{\text { hochviskos }}$ & $\begin{array}{l}\text { Blatt } 4 \\
2,5 \text { YR } \\
2 / 4\end{array}$ \\
\hline 4 & $\begin{array}{l}\text { Orangenhonig } \\
\text { Amerika }\end{array}$ & $\begin{array}{l}\text { * Salix } \\
\text { ** Citrus } \\
\text { ** Palmae, Persea, Acacia }\end{array}$ & kein & $\begin{array}{c}8 \\
\text { hochviskos }\end{array}$ & $\begin{array}{l}\text { Blatt } 2 \\
10 \text { YR } \\
6 / 6\end{array}$ \\
\hline 5 & $\begin{array}{l}\text { Orangenhonig } \\
\text { Israel }\end{array}$ & $\begin{array}{l}{ }^{* *} \overline{\text { Citrus, Eucalyptus }} \\
\text { *** Trifolium repens, Tr. pratense (Ty- } \\
\text { pus), Labiatae M., Cruciferae }\end{array}$ & kein & 7 & $\begin{array}{c}\text { Blatt } 1 \\
2,5 \mathrm{Y} \\
8 / 4\end{array}$ \\
\hline 6 & $\begin{array}{l}\text { Blütenhonig } \\
\text { Ajoie } \\
\text { Schweiz }\end{array}$ & $\begin{array}{l}\text { * } \text { Cruciferae (Brassica) } \\
\text { ** Acer } \\
\text { *** Taraxacum, Salix, Obstbäume, } \\
\text { Rubus }\end{array}$ & kein & $\begin{array}{c}8 \\
\text { fest }\end{array}$ & $\underset{6 / 8}{\text { Blatt } 2}$ \\
\hline 7 & $\begin{array}{l}\text { Blütenhonig } \\
\text { Schweiz }\end{array}$ & $\begin{array}{l}{ }^{* *} \text { Cruciferae (Brassica) } \\
* * * \text { Acer, Taraxacum, Obstbäume, Myo- } \\
\text { sotis, Trifolium repens, Tr. pratense }\end{array}$ & kein & $\begin{array}{c}8 \\
\text { est }\end{array}$ & $\begin{array}{c}\text { Blatt } 2 \\
2,5 \mathrm{Y} \\
6 / 8\end{array}$ \\
\hline *** & $\begin{array}{l}\text { Leitpollen - p } \\
\text { Begleitpollen - } \\
\text { Einzelpollen - }\end{array}$ & $\begin{array}{l}\text { Ilen dominant } \\
\text { pollen d'accompagnement } \\
\text { pollen isolé }\end{array}$ & & & \\
\hline
\end{tabular}

1. Für die chemische Untersuchung dieser Honige, siehe Tabelle 4, Seite 69 .

Pour l'analyse chimique de ces miels, voir le tableau 4, page 69 . 
Тав. 3. - Bezeichnung, Pollenspektrum, Kristallisationsgrad und Farbtyp der untersuchten Honige ${ }^{1}$ TABL. 3. - Désignation, spectre pollinique, degré de cristallisation et couleur des miels analysés

\begin{tabular}{|c|c|c|c|c|c|}
\hline Nr. & $\begin{array}{c}\text { Bezeichnung } \\
\text { Désignation }\end{array}$ & $\begin{array}{l}\text { Pollenspektrum } \\
\text { Spectre pollinique }\end{array}$ & $\begin{array}{l}\text { Honigtau- } \\
\text { anteil } \\
\text { Indicateurs } \\
\text { de miellat }\end{array}$ & $\begin{array}{l}\text { Kristallisa- } \\
\text { tionsgrad } \\
\text { Cristallisation }\end{array}$ & $\begin{array}{c}\text { Farbtyp } \\
\text { Couleur }\end{array}$ \\
\hline 8 & $\begin{array}{c}\text { «Arctic » } \\
\text { Nordamerika }\end{array}$ & $\begin{array}{l}\text { * Cruciferae } \\
\text { ** Trifolium repens, Melilotus } \\
\text { *** Trifolium pratense, Cirsium, Caryo- } \\
\text { phyllaceae }\end{array}$ & kein & $\stackrel{8}{\text { fest }}$ & $\begin{array}{l}\text { Blatt } 1 \\
2,5 \mathrm{Y} \\
7 / 4\end{array}$ \\
\hline 9 & $\begin{array}{l}\text { Blütenhonig } \\
\text { China }\end{array}$ & $\begin{array}{l}* \text { * } \\
\text { **uciferae } \\
\text { Trifolium repens, Vicia, Allium, Sesa- } \\
\text { mus, Thalietrum, Fagopyrum }\end{array}$ & kein & $\stackrel{8}{\text { hochviskos }}$ & $\begin{array}{l}\text { Blatt } 2 \\
10 \mathrm{YR} \\
6 / 6\end{array}$ \\
\hline 10 & $\begin{array}{l}\text { Pampashonig } \\
\text { Argentinien }\end{array}$ & 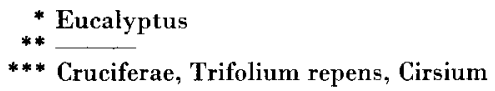 & kein & $\stackrel{8}{\text { hochviskos }}$ & $\begin{array}{l}\text { Blatt } 1 \\
2,5 \text { Y } \\
6 / 4\end{array}$ \\
\hline 11 & $\begin{array}{l}\text { Blütenhonig } \\
\text { Madagaskar }\end{array}$ & *** Eucalyptus & kein & $\stackrel{8}{\text { hochviskos }}$ & $\begin{array}{l}\text { Blatt } 2 \\
10 \text { YR } \\
5 / 6\end{array}$ \\
\hline 12 & $\begin{array}{l}\text { Blütenhonig } \\
\text { Australien }\end{array}$ & *** Eucalyptus & kein & 0 & $\begin{array}{l}\text { Blatt } 4 \\
2,5 \text { YR } \\
2 / 4\end{array}$ \\
\hline 13 & $\begin{array}{l}\text { Sonnenblu- } \\
\text { menhonig } \\
\text { Ausland }\end{array}$ & $\begin{array}{l}\text { * Eucalyptus } \\
\text { ** Helianthus } \\
\text { *** Erica sp., Onohrychis, Cistus, Labia- } \\
\text { tae M., Helianthemum }\end{array}$ & kein & $\begin{array}{c}8 \\
\text { fest }\end{array}$ & $\begin{array}{l}\text { Blatt } 3 \\
7,5 \text { Y R } \\
5 / 8\end{array}$ \\
\hline I4 & $\begin{array}{l}\text { Hochlandho- } \\
\text { nig, China }\end{array}$ & $\begin{array}{l}\text { * « Labiatae L. » } \\
\text { ** Vicia } \\
\text { *** Cruciferae, Labiatae M., Umbelliferae }\end{array}$ & kein & $\begin{array}{c}8 \\
\text { fest }\end{array}$ & $\begin{array}{l}\text { Blatt } 1 \\
2,5 \mathrm{Y} \\
7 / 4\end{array}$ \\
\hline 15 & $\begin{array}{l}\text { Blütenhonig } \\
\text { Costa Rica }\end{array}$ & $\begin{array}{l}\text { * Moraceae } \\
\text { ** Bombax, Compositae } \\
\text { *** Bursera, Manihot, Hydrophylaceae }\end{array}$ & kein & $\stackrel{8}{\text { hochviskos }}$ & $\begin{array}{l}\text { Blatt } 2 \\
10 \text { YR } \\
6 / 6\end{array}$ \\
\hline 16 & $\begin{array}{l}\text { Palmenhonig } \\
\text { karibisch }\end{array}$ & $\begin{array}{l}\text { * Palmae } \\
\text { ** Eucalyptus } \\
\text { *** Mimosa pudica, Compositae, Labia- } \\
\text { tae M. }\end{array}$ & kein & 0 & $\begin{array}{l}\text { Blatt } 3 \\
2,5 \text { Y R } \\
4 / 8\end{array}$ \\
\hline 17 & $\begin{array}{l}\text { Zuekerrohr- } \\
\text { honig, Cuba }\end{array}$ & 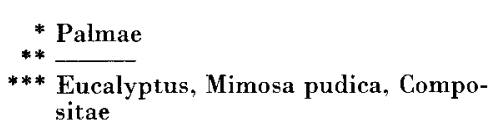 & kein & 0 & $\begin{array}{l}\text { Blatt } 4 \\
2,5 \text { YR }\end{array}$ \\
\hline 18 & $\begin{array}{l}\text { Akazienhonig } \\
\text { Ausland }\end{array}$ & $\begin{array}{l}\text { ** } \\
\text { **obinia, Eucalyptus } \\
\text { ** Cruciferae, Castanea, Trifolium re- } \\
\text { pens, Tilia, Loranthus, Onobrychis }\end{array}$ & kein & 0 & $\begin{array}{c}\text { Blatt } 3 \\
7,5 Y \\
5 / 8\end{array}$ \\
\hline
\end{tabular}


TAB. 3. - Bezeichnung, Pollenspektrum, Kristallisationsgrad und Farbtyp der untersuchten Honige ${ }^{*}$

TABL. 3. - Désignation, spectre pollinique, degré de cristallisation et couleur des miels analysés

\begin{tabular}{|c|c|c|c|c|c|}
\hline Nr. & $\begin{array}{c}\text { Bezeichnung } \\
\text { Désignation }\end{array}$ & $\begin{array}{l}\text { Pollenspektrum } \\
\text { Spectre pollinique }\end{array}$ & $\begin{array}{l}\text { Honigtau- } \\
\quad \text { anteil } \\
\text { Indicateurs } \\
\text { de micllat }\end{array}$ & $\begin{array}{l}\text { Kristallisa- } \\
\text { tionsgrad } \\
\text { Cristallisation }\end{array}$ & $\begin{array}{c}\text { Farbtyp } \\
\text { Couleur }\end{array}$ \\
\hline 19 & $\begin{array}{l}\text { Akazienhonig } \\
\text { Ungarn }\end{array}$ & $\begin{array}{l}\text { * Robinia } \\
\text { ** Cruciferae } \\
\text { *** Trifolium repens, Tr. incarnatum, } \\
\text { Vicia, Lotus, Medicago }\end{array}$ & kein & 0 & $\begin{array}{l}\text { Blatt } 4 \\
10 \text { YR }\end{array}$ \\
\hline 20 & $\begin{array}{l}\text { Rosmarin- } \\
\text { honig, Spanien }\end{array}$ & $\begin{array}{l}\text { * Hypecoum } \\
\text { ** Rosmarinus } \\
* * * \text { Labiatae M., Rubus }\end{array}$ & kein & $\stackrel{8}{\text { fest }}$ & $\begin{array}{l}\text { Blatt } 1 \\
2,5 \mathrm{Y} \\
8 / 4\end{array}$ \\
\hline 21 & $\begin{array}{l}\text { Wildblüten- } \\
\text { honig, Nord- } \\
\text { amerika }\end{array}$ & $\begin{array}{l}\text { ** Trifolium repens } \\
\text { *** Trifolium pratense, Medicago, Cir- } \\
\text { sium, Cruciferae }\end{array}$ & kein & $\stackrel{8}{\text { hochviskos }}$ & $\begin{array}{l}\text { Blatt } 2 \\
10 \text { Y } \\
6 / 6\end{array}$ \\
\hline 22 & $\begin{array}{l}\text { Wildblüten- } \\
\text { honig, Nord- } \\
\text { amerika }\end{array}$ & ** $\frac{\text { Trifolium repens }}{\text { *** Trifolium pratense, Medicago, Cir- }} \underset{\text { sium, Cruciferae }}{\text { Tium, }}$ & kein & $\stackrel{8}{\text { hochviskos }}$ & $\begin{array}{l}\text { Blatt } 2 \\
10 \mathrm{YR}\end{array}$ \\
\hline 23 & $\begin{array}{l}\text { Wiesenblï- } \\
\text { tenhonig } \\
\text { Neuseeland }\end{array}$ & $\begin{array}{l}* \text { Trifolium repens } \\
* * * \text { Trifolium pratense, Vicia, Cruciferae }\end{array}$ & kein & $\stackrel{8}{\text { hochviskos }}$ & $\underset{8 / 4}{\text { Blatt } 1}$ \\
\hline
\end{tabular}

2. Blüten-Mischhonige - Miels de fleurs mélangés

\begin{tabular}{|c|c|c|c|c|c|}
\hline 24 & $\begin{array}{l}\text { Bienenhonig } \\
\text { Sehweiz }\end{array}$ & $\begin{array}{l}{ }^{*} \overline{\text { Rhododendron, Rubus }} \\
\text { *** Trifolium pratense, Hippocrepis, Sa- } \\
\text { lix, Campanula, Polygonum bistorta }\end{array}$ & kein & $\begin{array}{c}8 \\
\text { fest }\end{array}$ & $\begin{array}{c}\text { Blatt 2 } \\
\text { 10 YR } \\
6 / 6\end{array}$ \\
\hline 25 & $\begin{array}{l}\text { Alpenrosen- } \\
\text { honig, Aus- } \\
\text { land }\end{array}$ & $\begin{array}{l}{ }^{*} \text { Rhododendron, Rubus } \\
\text { *** Onobrychis, Lotus, Hippocrepis, } \\
\text { Robinia, Castanea, Trifolium repens }\end{array}$ & kein & $\stackrel{8}{\text { hochviskos }}$ & $\begin{array}{c}\text { Blatt } 2 \\
10 \text { YR } \\
6 / 6\end{array}$ \\
\hline 26 & $\begin{array}{l}\text { Kleehonig } \\
\text { Ausland }\end{array}$ & $\begin{array}{l}\text { ** Trifolium repens, Cruciferae } \\
\text { *** Melilotus, Trifolium pratense, Salix, } \\
\text { Trifolium incarnatum, Labiatae M., } \\
\text { Acer }\end{array}$ & kein & $\stackrel{8}{\text { hochviskos }}$ & $\begin{array}{c}\text { Blatt 1 } \\
2,5 \mathrm{Y} \\
7 / 4\end{array}$ \\
\hline 27 & $\begin{array}{l}\text { Weissklee- } \\
\text { honig, Aus- } \\
\text { land }\end{array}$ & $\begin{array}{l}\text { ** Trifolium repens, Cruciferae } \\
\text { *** Trifolium pratense, Medicago, Hedy- } \\
\text { sarum, Eucalyptus, Tilia, Cistus, Cas- } \\
\text { tanea, Echium, Helianthus }\end{array}$ & kein & $\begin{array}{c}8 \\
\text { hochviskos }\end{array}$ & $\begin{array}{c}\text { Blatt 1 } \\
2,5 \mathrm{Y} \\
7 / 4\end{array}$ \\
\hline 28 & $\begin{array}{l}\text { Wiesenblï- } \\
\text { tenhonig } \\
\text { Ungarn }\end{array}$ & $\begin{array}{l}{ }^{*} \\
{ }^{* *} \text { Cruciferae } \\
\text { Robinia, Tilia, Salix, Onobrychis, } \\
\text { Cerinthe, Centaurea c. }\end{array}$ & kein & $\stackrel{8}{\text { hochviskos }}$ & $\begin{array}{c}\text { Blatt } 3 \\
7,5 \text { YR } \\
5 / 8\end{array}$ \\
\hline
\end{tabular}


TAв. 3. - Bezeichnung, Pollenspektrum, Kristallisationsgrad und Farbtyp der untersuchten Honige'

TABL. 3. - Dêsignation, spectre pollinique, degré de cristallisation et couleur des miels analysés

\begin{tabular}{|c|c|c|c|c|c|}
\hline Nr. & $\begin{array}{l}\text { Bezeichnung } \\
\text { Désignation }\end{array}$ & $\begin{array}{l}\text { Pollenspektrum } \\
\text { Spectre pollinique }\end{array}$ & $\begin{array}{l}\text { Honigtau- } \\
\text { anteil } \\
\text { Indicateurs } \\
\text { de miellat }\end{array}$ & $\begin{array}{l}\text { Kristallisa- } \\
\text { tionsgrad } \\
\text { Cristallisation }\end{array}$ & $\begin{array}{c}\text { Farbtyp } \\
\text { Couleur }\end{array}$ \\
\hline 29 & $\begin{array}{l}\text { Akazienhonig } \\
\text { Jugoslawien }\end{array}$ & $\begin{aligned} & * \overline{\text { Cruciferae }} \\
& * * * \text { Robinia, Onobrychis, Trifolium pra- } \\
& \text { tense, Tr. incarnatum, Lotus, Salix }\end{aligned}$ & kein & $\stackrel{8}{\text { hochviskos }}$ & $\begin{array}{c}\text { Blatt 2 } \\
2,5 \mathrm{Y} \\
6 / 8\end{array}$ \\
\hline 30 & $\begin{array}{l}\text { Blütenhonig } \\
\text { Jugoslawien }\end{array}$ & $\begin{array}{l}{ }^{*} \overline{\text { Cruciferae, Helianthus }} \\
\text { *** Trifolium repens, Lotus, Centaurea } \\
\text { c., Tilia, Acer, Rubus, Fagopyrum, } \\
\text { Impatiens, Labiatae M., Loranthus }\end{array}$ & kein & $\begin{array}{c}8 \\
\text { hochviskos }\end{array}$ & $\begin{array}{l}\text { Blatt } 2 \\
10 \text { YR } \\
5 / 6\end{array}$ \\
\hline 31 & $\begin{array}{l}\text { Blütenhonig } \\
\text { Italien }\end{array}$ & $\begin{array}{l}\text { ** Castanea, Eucalyptus } \\
\text { *** Cruciferae, Trifolium repens, Lotus, } \\
\text { Onobrychis, Robinia, Centaurea c. }\end{array}$ & kein & $\stackrel{8}{\text { hochviskos }}$ & $\begin{array}{l}\text { Blatt } 2 \\
2,5 Y \\
7 / 8\end{array}$ \\
\hline 32 & $\begin{array}{l}\text { Bienenhonig } \\
\text { Ausland }\end{array}$ & $\begin{array}{l}\text { ** Compositae, Proteaceae, Eucalyptus } \\
\text { *** Mimosa pudica, Citrus, Olea, Persea, } \\
\text { Bombax, Bursera, Ephedra, Hydro- } \\
\text { phyllaceae, Labiatae M. }\end{array}$ & kein & $\begin{array}{c}8 \\
\text { fest }\end{array}$ & $\begin{array}{l}\text { Blatt } 2 \\
10 \text { YR } \\
5 / 6\end{array}$ \\
\hline 33 & $\begin{array}{l}\text { Gebirgshonig } \\
\text { Amerika }\end{array}$ & $\begin{array}{l}\text { ** } \\
\text { *** Compositae, Mimosa pudica } \\
\text { Eucalyptus, Citrus, Persea, Palmae, } \\
\text { Labiatae, S., M., Acacia }\end{array}$ & kein & $\stackrel{8}{\text { hochviskos }}$ & $\begin{array}{c}\text { Blatt } 2 \\
2,5 \mathrm{Y} \\
7 / 8\end{array}$ \\
\hline 34 & $\begin{array}{l}\text { "Cowboy " } \\
\text { Amerika }\end{array}$ & $\begin{aligned} &{ }^{*} \overline{\text { Mimosa pudica, Eucalyptus }} \\
& * * * \text { Compositae, Gossypium, Acacia, La- } \\
& \text { biatae S. }\end{aligned}$ & kein & $\stackrel{8}{\text { hochviskos }}$ & $\begin{array}{c}\text { Blatt } 2 \\
2,5 \mathrm{Y} \\
6 / 8\end{array}$ \\
\hline 35 & $\begin{array}{l}\text { Blütenhonig } \\
\text { Mexiko }\end{array}$ & 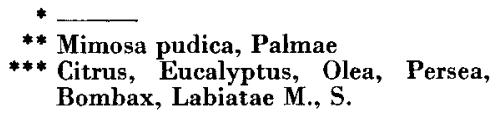 & kein & 6 & $\begin{array}{l}\text { Blatt } 2 \\
10 \underset{7 / 6}{Y} \mathbf{R}\end{array}$ \\
\hline
\end{tabular}

\section{Einseitige Waldhonige - Miels de miellat}

\begin{tabular}{|c|c|c|c|c|c|}
\hline 36 & $\begin{array}{l}\text { Waldhonig } \\
\text { Sehweiz }\end{array}$ & 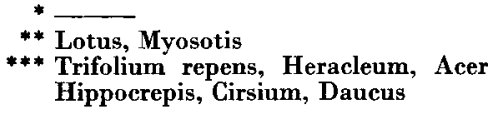 & sehr viel & $\stackrel{8}{\text { hochviskos }}$ & $\begin{array}{c}\text { Blatt } 4 \\
2,5 \mathrm{Y} \\
2 / 2\end{array}$ \\
\hline 37 & $\begin{array}{l}\text { Tannenhonig } \\
\text { Ausland }\end{array}$ & $\begin{array}{l}\text { ** } \\
\text { *** Trifolium repens, Cruciferae } \\
\text { Trifolium pratense, Robinia, Fagopy- } \\
\text { rum, Labiatae M., Helianthus, Cen- } \\
\text { taurea c. }\end{array}$ & sehr viel & $\begin{array}{c}8 \\
\text { fest }\end{array}$ & $\begin{array}{c}\text { Blatt } 4 \\
2,5 \text { YR } \\
2 / 2\end{array}$ \\
\hline
\end{tabular}

1. Siehe Tabelle 4, Seite 72.

Voir tableau 4, page 72 . 
TAB. 3. - Bezeichnung, Pollenspektrum, Kristallisationsgrad und Farbtyp der untersuchten Honige ${ }^{1}$

TABL. 3. - Désignation, spectre pollinique, degré de cristallisation et couleur des miels analysés

\begin{tabular}{|c|c|c|c|c|c|}
\hline Nr. & $\begin{array}{c}\text { Bezeichnung } \\
\text { Désignation }\end{array}$ & $\begin{array}{l}\text { Pollenspektrum } \\
\text { Spectre pollinique }\end{array}$ & $\begin{array}{l}\text { Honigtau- } \\
\text { anteil } \\
\text { Indicateurs } \\
\text { de miellat }\end{array}$ & $\begin{array}{l}\text { Kristallisa- } \\
\text { tionsgrad } \\
\text { Cristallisation }\end{array}$ & $\begin{array}{c}\text { Farbtyp } \\
\text { Couleur }\end{array}$ \\
\hline 38 & $\begin{array}{l}\text { Bienenhonig } \\
\text { Schweiz }\end{array}$ & 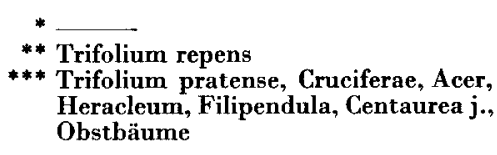 & viel & $\begin{array}{c}8 \\
\text { fest }\end{array}$ & $\begin{array}{c}\text { Blatt } 1 \\
2,5 \mathrm{Y} \\
4 / 4\end{array}$ \\
\hline 39 & $\begin{array}{l}\text { Tannenhonig } \\
\text { Schwarzwald } \\
\text { B.R.D. }\end{array}$ & $\begin{array}{l}\text { ** } \\
\text { *** Trifolium repens, Tr. pratense } \\
\text { Heracleum, Daucus, Cruciferae, Myo- } \\
\text { sotis, Campanula, Acer, Sambucus }\end{array}$ & viel & 7 & $\begin{array}{l}\text { Blatt } 1 \\
2,5 Y \\
3 / 4\end{array}$ \\
\hline 40 & $\begin{array}{l}\text { Waldhonig } \\
\text { Schweiz }\end{array}$ & 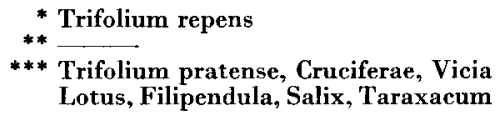 & viel & $\begin{array}{c}8 \\
\text { fest }\end{array}$ & $\begin{array}{l}\text { Blatt } 2 \\
10 \text { YR } \\
5 / 6\end{array}$ \\
\hline
\end{tabular}

4. Mischhonige aus Blüten -und Waldtracht - Miels de fleurs mélangês de miels de miellat

\begin{tabular}{|c|c|c|c|c|c|}
\hline 41 & $\begin{array}{l}\text { Blütenhonig } \\
\text { Bulgarien }\end{array}$ & $\begin{array}{l}\text { ** Trifolium repens } \\
\text { *** Trifolium pratense, Melilotus, Vicia, } \\
\text { Rubus, Helianthus, Cirsium, Cruci- } \\
\text { ferae, Labiatae M., Centaurea c., j., } \\
\text { Eucalyptus }\end{array}$ & $\begin{array}{l}\text { ziemlich } \\
\text { viel }\end{array}$ & $\begin{array}{c}8 \\
\text { fest }\end{array}$ & $\begin{array}{l}\text { Blatt } 3 \\
7,5 \text { YR } \\
5 / 8\end{array}$ \\
\hline 42 & $\begin{array}{l}\text { Waldhonig } \\
\text { Rumänien }\end{array}$ & $\begin{aligned} & * \text { Trifolium repens } \\
& * * * \text { Cruciferae, Trifolium pratense, Salix, } \\
& \text { Onobrychis, Vicia, Lotus, Rubus, } \\
& \text { Robinia, Helianthus, Centaurea c., } \\
& \text { Cirsium, Lythrum, Labiatae M. }\end{aligned}$ & $\begin{array}{l}\text { ziemlich } \\
\text { viel }\end{array}$ & 7 & $\begin{array}{l}\text { Blatt } 4 \\
2,5 \text { YR } \\
2 / 2\end{array}$ \\
\hline 43 & $\begin{array}{l}\text { Blütenhonig } \\
\text { Rumänien }\end{array}$ & $\begin{array}{l}\text { ** Cruciferae, Helianthus, Trifolium } \\
\text { repens } \\
\text { Robinia, Tilia, Trifolium pratense, } \\
\text { Lythrum, Lotus, Cirsium, Centaurea } \\
\text { c., Rubus }\end{array}$ & $\begin{array}{l}\text { ziemlich } \\
\text { viel }\end{array}$ & $\stackrel{8}{\text { hochviskos }}$ & $\begin{array}{l}\text { Blatt 2 } \\
10 \text { YR } \\
5 / 6\end{array}$ \\
\hline 44 & $\begin{array}{l}\text { Waldhonig } \\
\text { Jugoslawien }\end{array}$ & $\begin{array}{l}\text { * Castanea } \\
\text { *** } \text { Cruciferae, Trifolium repens, Lotus, } \\
\text { Acer, Olea, Fagopyrum, Cannabis, } \\
\text { Lythrum }\end{array}$ & $\begin{array}{l}\text { ziemlich } \\
\text { viel }\end{array}$ & 0 & $\begin{array}{c}\text { Blatt } 4 \\
2,5 \text { YR } \\
2 / 2\end{array}$ \\
\hline 45 & $\begin{array}{l}\text { Himbeer- } \\
\text { honig, Tsche- } \\
\text { choslowakei }\end{array}$ & $\begin{array}{l}{ }^{* *} \text { Trifolium repens } \\
\text { *** } \\
\text { Rubus, Labiatae M., Tilia, Lotus, } \\
\text { Salix, Filipendula, Robinia, Rham- } \\
\text { nus, Centaurea j., Echium }\end{array}$ & $\begin{array}{l}\text { ziemlich } \\
\text { viel }\end{array}$ & 0 & $\begin{array}{l}\text { Blatt } 4 \\
2,5 \text { YR } \\
2 / 2\end{array}$ \\
\hline
\end{tabular}

1. Siehe Tabelle 4, Seite 73 .

Voir Tableau 4, page 73 . 
TAB. 3. - Bezeichnung, Pollenspektrum, Kristallisationsgrad und Farbtyp der untersuchten Honige ${ }^{1}$

TaBL. 3. - Désignation, spectre pollinique, degré de cristallisation et couleur des miels analysés

\begin{tabular}{|c|c|c|c|c|c|}
\hline Nr. & $\begin{array}{l}\text { Bezeichnung } \\
\text { Désignation }\end{array}$ & $\begin{array}{l}\text { Pollenspektrum } \\
\text { Spectre pollinique }\end{array}$ & $\begin{array}{l}\text { Honigtau- } \\
\text { anteil } \\
\text { Indicateurs } \\
\text { de miellat }\end{array}$ & $\begin{array}{l}\text { Kristallisa- } \\
\text { tionsgrad } \\
\text { Cristallisation }\end{array}$ & $\begin{array}{l}\text { Farbtyp } \\
\text { Couleur }\end{array}$ \\
\hline 46 & $\begin{array}{l}\text { Waldblüten- } \\
\text { honig, Tsche- } \\
\text { choslowakei }\end{array}$ & $\begin{array}{l}{ }^{*} \text { Trifolium repens, Rubus, Cruciferae } \\
\text { *** Trifolium pratense, Robinia, Vicia, } \\
\text { Onobrychis, Lotus, Labiatae M. }\end{array}$ & $\begin{array}{l}\text { ziemlich } \\
\text { viel }\end{array}$ & $\begin{array}{c}8 \\
\text { fest }\end{array}$ & $\begin{array}{l}\text { Blatt } 4 \\
2,5 \text { YR } \\
2 / 4\end{array}$ \\
\hline 47 & $\begin{array}{l}\text { Bienenhonig } \\
\text { Schweiz }\end{array}$ & $\begin{array}{l}\text { * Castanea } \\
\text { *** Trifolium repens, Tr. pratense, Tilia, } \\
\text { Onobrychis, Lotus, Robinia, Vicia, } \\
\text { Lythrum, Centaurea j., Helianthus, } \\
\text { Erica sp., Daucus, Labiatae S. }\end{array}$ & $\begin{array}{l}\text { ziemlich } \\
\text { viel }\end{array}$ & $\stackrel{8}{\text { hochviskos }}$ & $\begin{array}{l}\text { Blatt } 2 \\
10 \mathrm{YR} \\
4 / 6\end{array}$ \\
\hline 48 & $\begin{array}{l}\text { Waldhonig } \\
\text { Frankreich }\end{array}$ & $\begin{array}{l}\text { * } \text { Castanea } \\
\text { *** } \frac{\text { Rubus, Onobrychis, Calluna, Labia- }}{\text { tae M., Vicia, Lotus, Cirsium, Cen- }} \\
\text { taurea c., j., Geranium, Erica sp., } \\
\text { Cistus }\end{array}$ & wenig & 0 & $\begin{array}{l}\text { Blatt } 4 \\
2,5 \mathrm{Y} \\
2 / 2\end{array}$ \\
\hline 49 & $\begin{array}{l}\text { Salbeihonig } \\
\text { Jugoslawien }\end{array}$ & $\begin{array}{l}\text { ** Castanea, Labiatae S. (Salvia) } \\
\text { *** Tilia, Trifolium repens, Robinia, } \\
\text { Lotus, Vitis, Labiatae M., Helian- } \\
\text { thus, Olea, Fagopyrum, Pastinaca, } \\
\text { Echium }\end{array}$ & wenig & 5 & $\begin{array}{c}\text { Blatt } 4 \\
2,5 \mathrm{Y} \\
2 / 4\end{array}$ \\
\hline 50 & $\begin{array}{l}\text { Lindenhonig } \\
\text { Rumänien }\end{array}$ & $\begin{array}{l}{ }^{*} \text { Tilia, Helianthus, Cruciferae } \\
\text { *** Trifolium repens, Tr. pratense, Lyth- } \\
\text { rum, Onobrychis, Daucus, Cirsium }\end{array}$ & wenig & 7 & $\begin{array}{l}\text { Blatt } 2 \\
2,5 \mathrm{Y} \\
6 / 8\end{array}$ \\
\hline 51 & $\begin{array}{l}\text { Lindenhonig } \\
\text { Rumänien }\end{array}$ & $\begin{array}{l}\text { ** Tilia, Helianthus, Trifolium repens } \\
\text { *** Cruciferae, Onobrychis, Daucus, } \\
\text { Lotus, Cirsium, Salix, Centaurea c. }\end{array}$ & wenig & 6 & $\begin{array}{l}\text { Blatt } 2 \\
2,5 \mathrm{Y} \\
7 / 8\end{array}$ \\
\hline 52 & $\begin{array}{l}\text { Lindenhonig } \\
\text { Ausland }\end{array}$ & $\begin{array}{l}{ }^{* *} \text { Trifolium repens, Cruciferae, Euca- } \\
\text { lyptus } \\
\text { Tilia, Helianthus, Rhamnus, Echium }\end{array}$ & wenig & 7 & $\begin{array}{l}\text { Blatt } 2 \\
10 \underset{7 / 6}{Y R}\end{array}$ \\
\hline 53 & $\begin{array}{l}\text { Blütenhonig } \\
\text { San Salvador }\end{array}$ & $\begin{array}{l}{ }^{*}-\overline{\text { Coffea, Eucalyptus }} \\
\text { *** Mimosa pudica, Bursera, Acacia }\end{array}$ & wenig & 7 & $\begin{array}{l}\text { Blatt } 2 \\
10 \text { YR } \\
6 / 6\end{array}$ \\
\hline 54 & $\begin{array}{l}\text { Blütenhonig } \\
\text { San Salvador }\end{array}$ & $\begin{array}{l}{ }^{*} \text { Coffea } \\
* * \text { Eucalyptus } \\
* * * \text { Bursera, Acacia, Mimosa pudica }\end{array}$ & wenig & 7 & $\begin{array}{l}\text { Blatt } 2 \\
10 \text { YR } \\
6 / 6\end{array}$ \\
\hline
\end{tabular}

1. Siehe Tabelle 4 , Seite 74 .

Voir tableau 4, page 74 . 


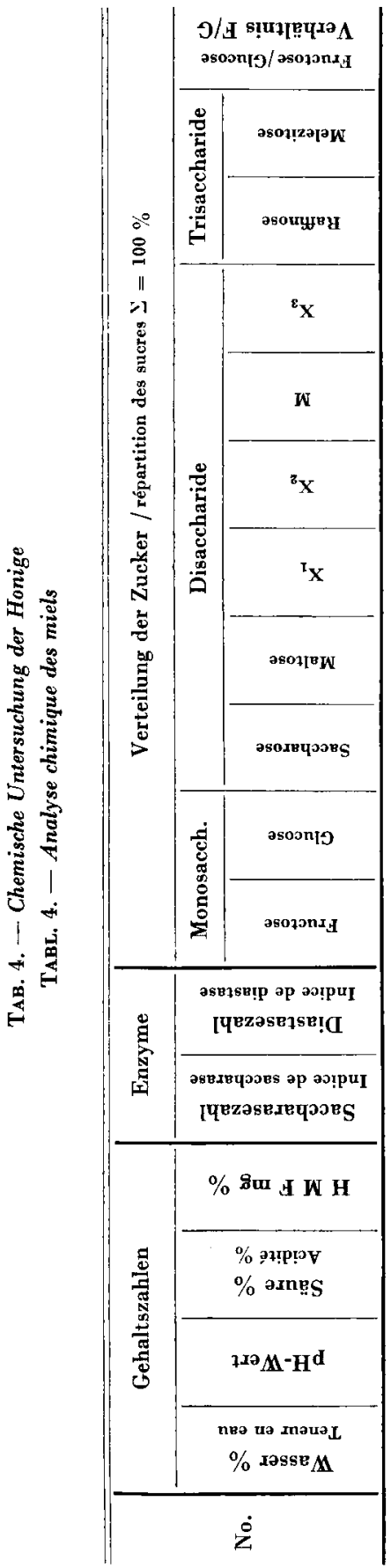

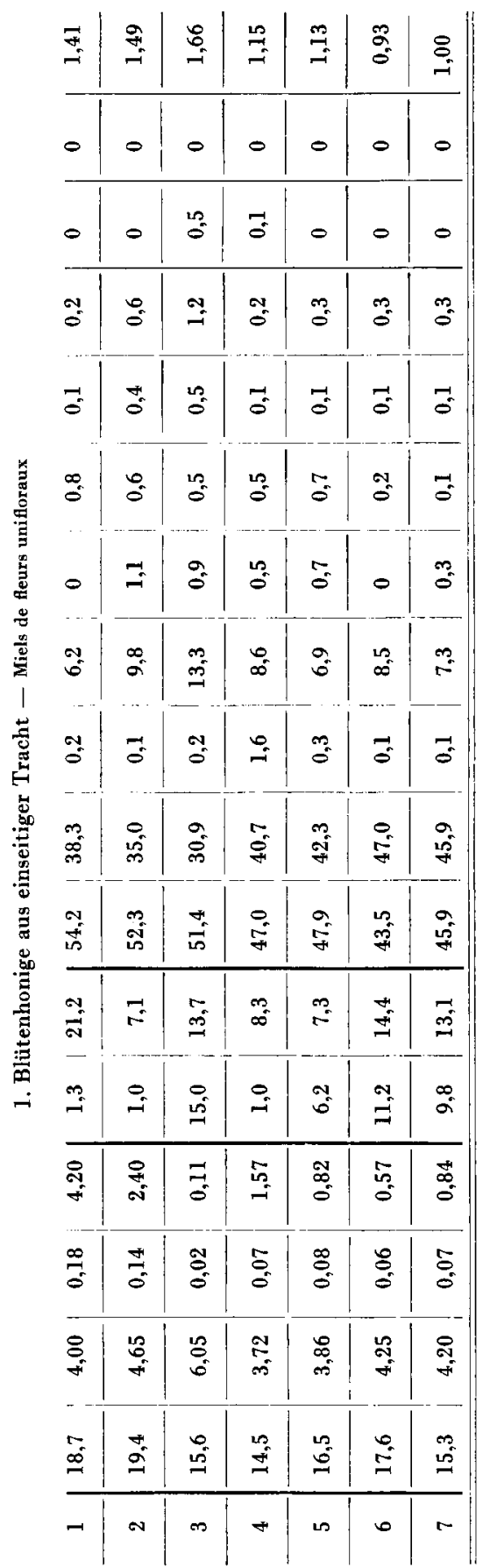




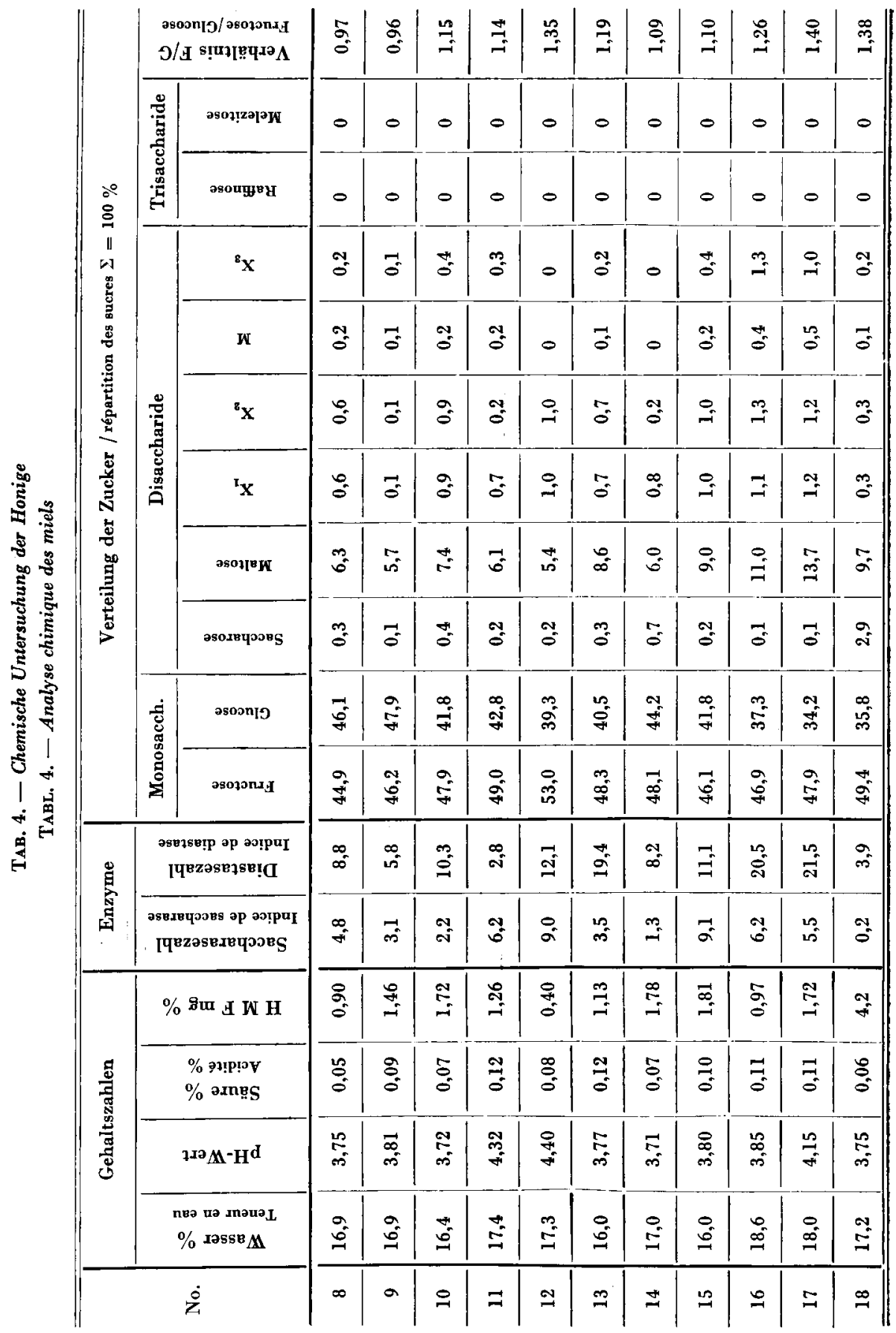




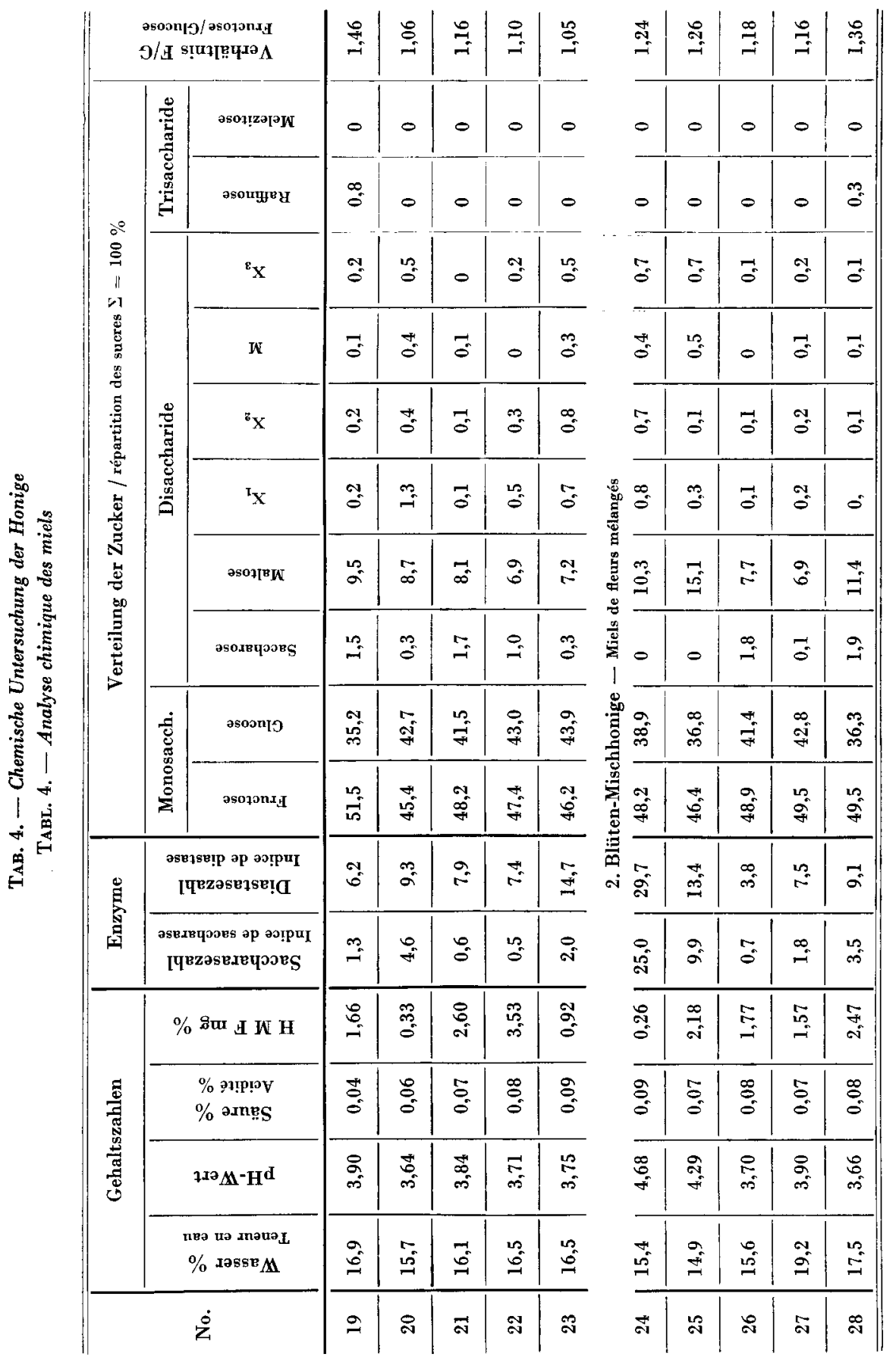




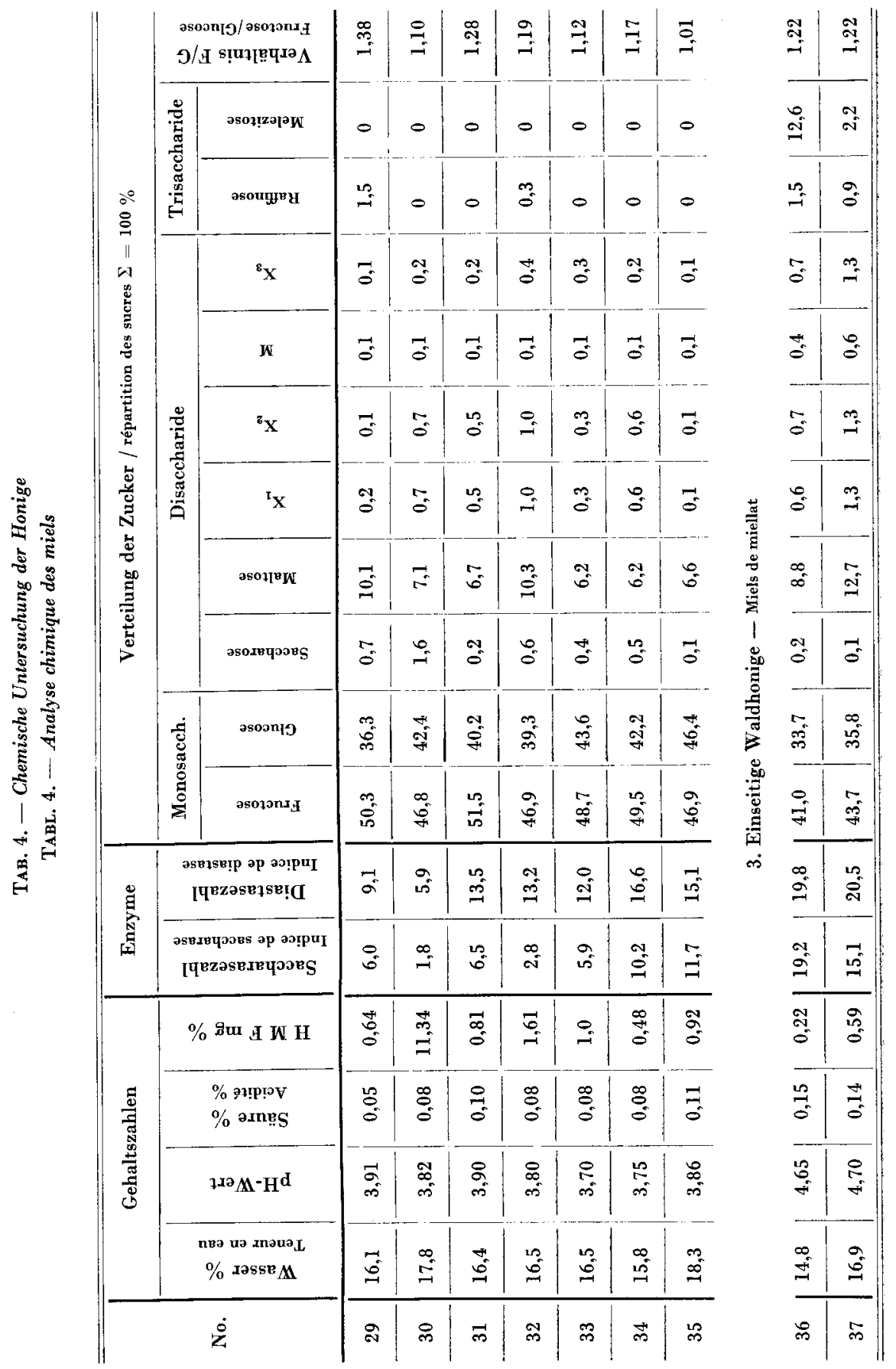




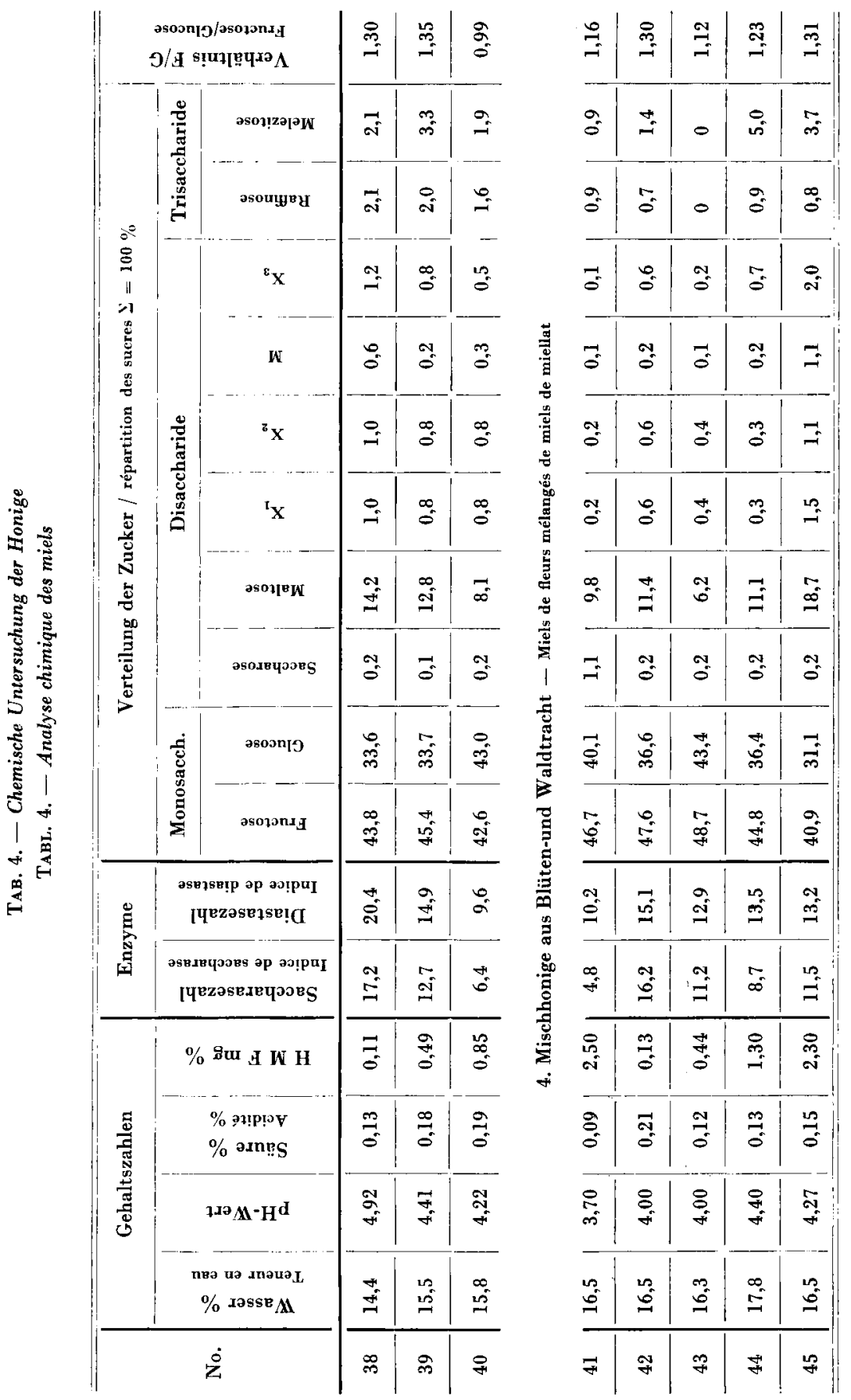




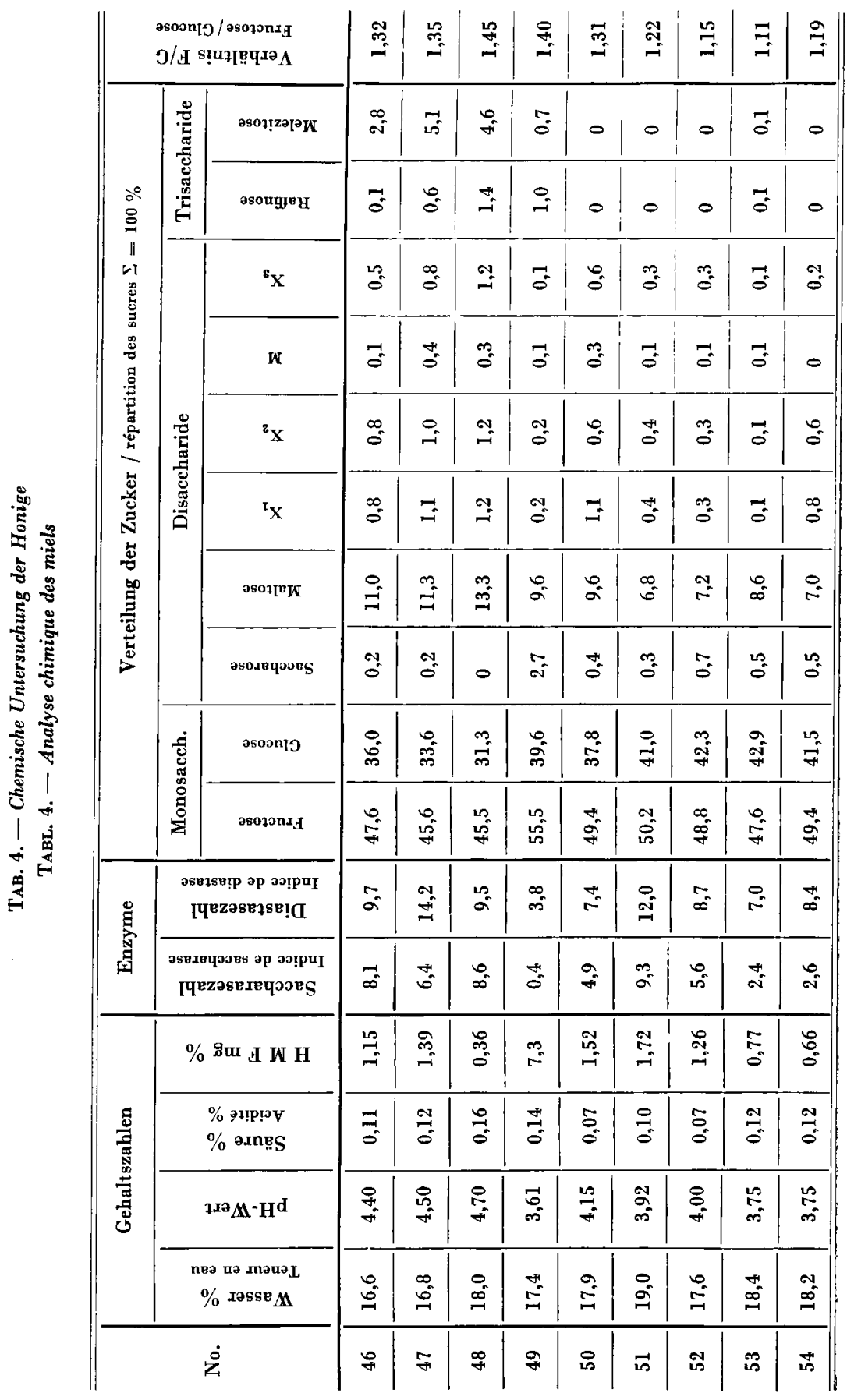


und Diastasezahl, gaschromatographische Bestimmung der Zuckerarten). Die Proben sind in den Tabellen auf Grund des mikroskopischen Bildes in 4 Gruppen eingeteilt, so dass Honige ähnlicher botanischer Herkunft unmittelbar untereinander stehen. Die Gruppen umfassen :

1. Blütenhonige aus einseitiger Tracht,

2. Blütenmischhonige,

3. Waldhonige aus einseitiger Tracht,

4. Mischhonige aus Blüten- und Waldtracht.

Gruppe 1 enthält Honige, die einen Leit- oder einen massgebenden Begleitpollen enthalten, und von welchen anzunehmen ist, dass sie aus einseitiger Nektartracht stammen. Innerhalb dieser Gruppe sind die Proben alphabetisch nach der lateinischen Bezeichnung der massgebenden Form angeordnet. In Gruppe 2 finden sich die Honige, die keine Leitform enthalten und aus Mischtracht von mehreren Nektarquellen stammen. Gruppe 3 vereinigt die Proben mit viel bis sehr viel Honigtaubestandteilen, die demnach zum guten Teil aus Honigtautracht stammen, Gruppe 4 die aus Nektar- und Honigtautracht stammenden Honige mit wenig bis ziemlich viel Honigtaubestandteilen.

\section{DISKUSSION DER RESULTATE}

\section{Mikroskopische Untersuchung}

In den meisten europäischen Ländern schreiben die Honigverordnungen eine Deklaration der Herkunft bei Honig vor. Nach der schweizerischen Lebensmittelverordnung muss Auslandhonig deutlich als solcher gekennzeichnet sein, Mischungen von Inland- und Auslandhonig werden als Auslandhonig behandelt. Auch Sortenbezeichnungen wie Blüten-oder Waldhonig, Orangenhonig, Linden- oder Alpenrosenhonig müssen stimmen, d. h. der betreffende Honig muss vorwiegend aus der angeführten Trachtquelle stammen. Wenn auch die physikalischen und chemischen Eigenschaften bis zu einem gewissen Grade zur Charakteristik der botanischen Herkunft von Sortenhonigen beitragen können (z. B. Thixotropie, elektrische Leitfähigkeit, Zuckerspektrum), bildet die mikroskopische Untersuchung des Honigsediments heute noch die sicherste Grundlage zur Bestimmung der geographischen und botanischen Herkunft bei Honig.

Die mikroskopische Untersuchung der vorliegenden 54 Honigproben verfolgte zwei Zwecke. Einerseits sollte festgestellt werden wieweit die auf den Etiketten gemachten Angaben über die geographische und sortenmässige Herkunft der Honige stimmen, anderseits sollten die Honige anhand des Pollenspektrums in Gruppen ähnlicher botanischer Herkunft zusammenge- 


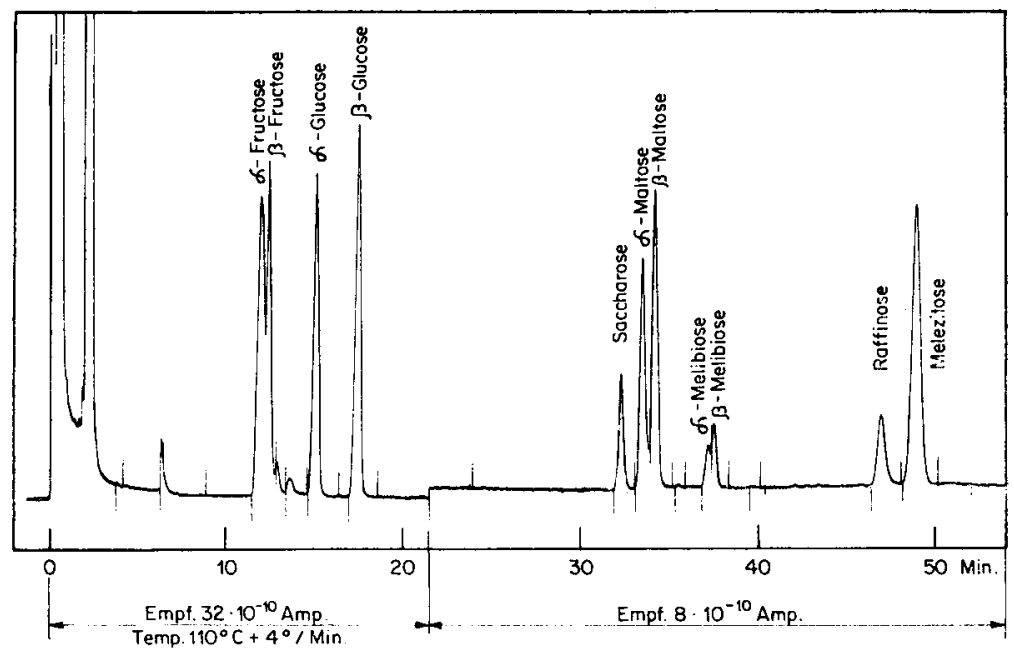

Aвв. 1. - Gaschromatogramm der Zuckersilyläther einer Zucker-Modellmischung

Fig. 1. - Chromatogramme en phase gazeuse des êthers silyliques d'un mélange de sucres de quantitê connue

Gaschromatographische Bedingungen

Glassäule innerer Durchmesser $1 / 8^{\prime \prime}$, Länge $2,1 \mathrm{~m}$

Säulenfüllung $3 \%$ OV-17 auf Aeropack - 30, 80/100 mesh

Einspritzmenge $1,5 \mu \mathrm{l}$

Trägergas $\mathrm{N}_{2}=30 \mathrm{ml} / \mathrm{min}$.

Flammenionisationsdetektor (FID)

Temperaturprogramm $110^{\circ} \mathrm{C}+6^{\circ} / \mathrm{min}$ bis $275^{\circ}$ Endtemperatur

Injektor- und Detektor-Temperatur $275^{\circ} \mathrm{C}$

Empfindlichkeit für die Registrierung der Monosaccharide 32.10-10 Amp.

für die Di- und Trisaccharide $8.10^{-10}$ Amp.

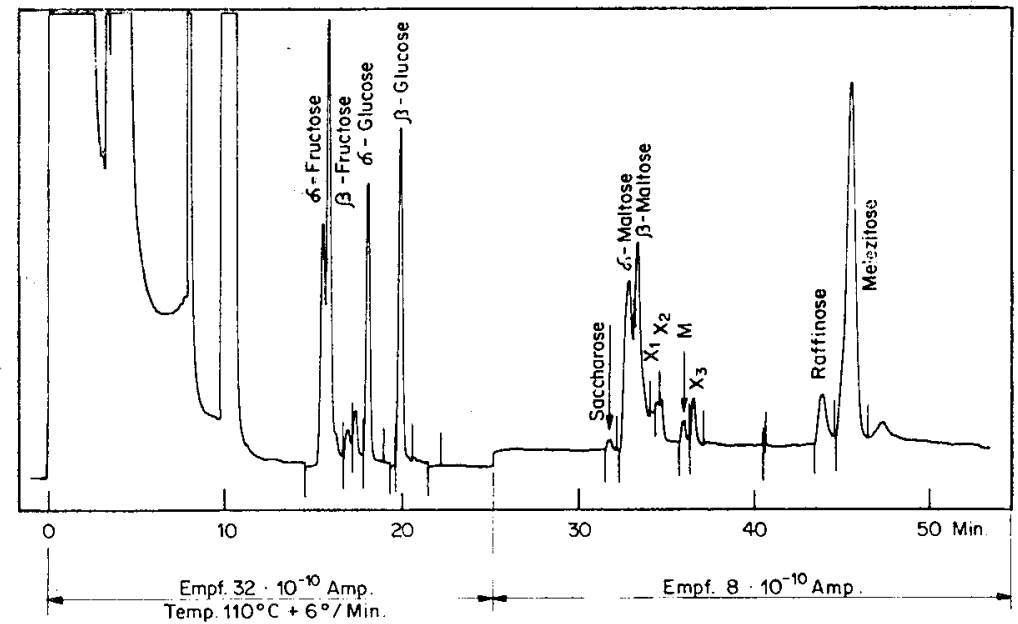

Aвв. 2. - Gaschromatogramm der Zuckersilyläther des Waldhonigs Nr. 36

Fıc. 2. - Chromatogramme en phase gazeuse des éthers silyliques des sucres du miel de miellat $\left(n^{\circ} 36\right)$ 
fasst werden, um eine bessere Deutung der Resultate der physikalischen und chemischen Analysen zu erlauben.

Auf den Etiketten der 54 Honige waren meist Angaben über das Ursprungsland (manchmal nur " Ausland ») und oft auch Sortenangaben vorhanden (zum Teil nur « Blüten- » oder “ Waldhonig », zum Teil Phantasiebezeichnungen wie " Cowboy- », " Arctic- " oder “ Pampas-Honig »). Viele der Etiketten trugen ausserdem Anpreisung wie “ echter », “ naturechter », “ naturbelassener », “ reiner » oder " naturreiner ) Honig, was aus Platzgründen in den Tabellen 3 und 4 weggelassen wurde.

Die Deklaration des Ursprungslandes stimmte, mit einer Ausnahme, bei allen untersuchten Proben. Die Ausnahme bildet der Honig Nr. 47, der als “ Schweizer Bienenhonig » deklariert war, nach dem Pollenbild aber eine leichte, doch deutliche Beimischung südosteuropäischen Honigs enthielt.

Bei einer Anzahl von Proben, die nur die Angabe “Ausland " oder “ Amerika » trugen, liess sich die Herkunft anhand des Pollenbildes näher umschreiben. So dürfte der " in der B.R.D. abgefüllte Heidehonig ” (Nr. 2) aus Spanien stammen (Louveaux 1974). Die als “ Ausland 》 deklarierten Proben Nr. 13, 18, 37 und 52 zeigen die Merkmale südosteuropäischer Honige; die Proben Nr. 25 und 27 dürften aus Italien stammen. Um mexikanische Honige handelt es sich vermutlich bei den als " Cowboy », " Gebirgshonig " und “ Bienenhonig » bezeichneten Proben Nr. 32, 33, 34; nordamerikanischer Herkunft dürfte dagegen die Probe Nr. 4 sein.

Im Vergleich zu den auf dem Pariser Honigmarkt herrschenden Verhältnissen, schneiden die untersuchten Schweizer Handelshonige in bezug auf die Herkunftsdeklaration gut ab. Trotzdem die französische Lebensmittelverordnung eine deutliche Deklaration der Herkunft bei Honig vorschreibt, fanden sich auf dem Pariser Markt verhältnismässig viele falsch etikettierte Packungen, sowie Mischungen von französischem und ausländischem Honig (Borneck, Louis und Louveaux 1958).

Während bei der Deklaration der geographischen Herkunft der untersuchten Honige die Vorschriften der Lebensmictelverordnung im allgemeinen eingehalten wurden, herrscht bei den Sortenbezeichnungen grösste Mannigfaltigkeit. So entpuppten sich unter den als “ Blütenhonig » oder « Bienenhonig 》 deklarierten Schweizerhonigen die Proben Nr. 6 und 7 als einseitige Rapshonige, die Proben Nr. 3 und 47 als Edelkastanien-, bzw. KastanienHonigtauhonig. Auch die als "Waldhonig " deklarierten Proben Nr. 44 und 48 aus Frankreich und Jugoslawien stammen zum guten Teil aus Edelkastanientracht. Einseitige Cruciferen-, bzw. Kleehonige sind die als “ Arctic » “ und Blütenhonig " bezeichneten Proben Nr. 8 und 9; um Weisskleehonige handelt es sich bei den beiden nordamerikanischen "Wildblütenhonigen 》 (Nr. 21, 22) und dem neuseeländischen “ Wiesenblütenhonig » (Nr. 14). Als 
(C Pampas- », “ Sonnenblumen- ) und “ Blütenhonig » sind 3 aus einseitiger Eucalyptustracht, und eine aus Eucalyptus- und Sonnenblumentracht stammende Proben bezeichnet (Nr. 10, 11, 12, 13).

In allen diesen Fällen ist die Bezeichnung “ Blütenhonig " nicht falsch, da die betreffenden Proben wirklich aus Nektartracht stammen; sie zeigt aber, ähnlich wie die Phantasiebezeichnungen "Cowboy », “ Pampas », " Arctic ", eine Tendenz zur Werbe-Aufwertung oder Verschleierung von Honigsorten, die wegen ihres auffälligen Geschmacks und Aromas beim Publikum weniger beliebt sind (z. B. Raps-, Kastanien-, Eucalyptushonig). Neben den Proben mit " aufwertender » Bezeichnung fand sich auch eine, deren Deklaration der wirklichen Herkunft nicht ganz gerecht wird - der schweizer “ Bienenhonig 》 Nr. 24, der nach dem Pollenbild als Berghonig aus Alpenrosen- und Himbeertracht bezeichnet werden kann.

Bei der Beurteilung der als “ Akazien-, Orangen-, Linden-, Salbei -und Rosmarinhonig 》 bezeichneten Proben muss berücksichtigt werden, dass erfahrungsgemäss die betreffenden Pollenarten im Honig unterrepräsentiert sind und ihre Befunde in der Pollenauszählung aufgewertet werden müssen (Intern. Kommission Bienenbotanik 1970). So kann die Sortenbezeichnung der Proben Nr. 4, 5, 18, 19 und 20 als richtig angenommen werden, trotzdem die Leitform darin nicht immer auf der Stufe des Leitpollens auftritt. Weniger überzeugend ist die Sortenbezeichnung bei den Proben Nr. 49, 50, 51 und 52, die teilweise aus Honigtautracht stammen und der als " Akazienhonig " deklarierten Probe Nr. 29, in der Robinienpollen nur vereinzelt zu finden war. Vollends falsch dürfte die Bezeichnung 》 Himbeerhonig » der Probe Nr. 45 sein, die nach dem Pollenbild aus Mischtracht von verschiedenen Pflanzen und von Honigtau stammt, mit sehr geringem Anteil von Rubus.

$\mathrm{Zu}$ den Proben mit auffallendstem Pollenbild gehören die beiden als "Blütenhonig 》 deklarierten und offenbar zum guten Teil aus Tracht von Kaffeesträuchern stammenden Proben aus San Salvador (Nr. 53, 54), der “ karibische Palmenhonig ", der ebenfalls vorwiegend Palmenpollen führende “Zuckerrohrhonig aus Kuba » (Nr. 16, 17), und der chinesische " Hochlandhonig " (Nr. 14), der einen bisher nicht sicher identifizierten Leitpollen enthält, bei dem es sich wahrscheinlich um eine Labiate des Typus a $L$ 》 handelt (Focke 1968, 1973).

Gute Uebereinstimmung zwischen der Deklaration und den mikroskopischen Befunden zeigen im allgemeinen die einseitigen Waldhonige und die Wald-Blütenhonige. Von den 5, nach dem mikroskopischen Befund aus einseitiger Honigtautracht stammenden, Proben waren 4 als “ Waldhonig » deklariert; unter den 8 Blüten-Wald-Mischhonigen, waren 3 als “ Blüten- », 4 als ( Wald- ) und einer als “ Bienenhonig » deklariert. Die meisten dieser Proben sind durch das Fehlen eines Leitpollens und einen vermehrten Anteil von Honigtaubestandteilen charakterisiert (Tab. 3, Gruppen 3 und 4). 
Weitere Einzelheiten der mikroskopischen Befunde werden im Zusammenhang mit den Resultaten der physikalischen und chemischen Analysen besprochen.

\section{Kristallisationsform}

Die Beurteilung der Kristallisation erfolgte erst nachdem die Honige ungefähr $1 \mathrm{Jahr}$ bei Zimmertemperatur gelagert waren. Nach dieser Zeit ist mit keiner grossen Veränderung mehr zu rechnen. Die flüssigen Honige dürften auch bei noch längerer Lagerung kaum kristallisieren. Unter den untersuchten Honigen entsprachen viele der von White und Mitarb. (1962) aufgestellten Skala von 10 Typen; andere liessen sich nicht richtig in diese Skala eingliedern (Tab. 1).

Die Kristallisationsform wird beein flusst, einerseits durch das Fruktose/ Glukose-Verhältnis, anderseits durch das Verhältnis zwischen dem Glukoseund dem Wassergehalt (White u. Mitarb. 1962).

Von den untersuchten Honigen blieben vor allem die mit einem hohen Fruktosegehalt flüssig (Fruktose/Glukose-Verhältnis 1,23-1,44), z. B. der Eucalyptushonig Nr. 12, zwei Palmenhonige (Nr. 16, 17), zwei Robinienhonige (Nr. 18, 19), zwei Kastanienhonige mit Waldeinschlag (Nr. 44, 48) und ein Mischhonig aus Blüten- und Waldtracht (Nr. 45).

Durch schonende technische Wärmebehandlung ist es heute möglich, das Kristallisieren des Honigs weitgehend zu verhindern. Dieses Verfahren erfordert grösste Sorgfalt, damit die Honig-Enzyme nicht geschädigt werden. Wie die stark abgeschwächte Enzymaktivität zeigt, sind mehrere der untersuchten Honige zweifellos stark erhitzt worden, in den Gläsern aber dennoch wieder kristallisiert. Dazu gehören z. B. der Chinahonig (Nr. 9), vier Kleehonige (Nr. 21, 22, 26, 27), die beiden Coffea-Eucalyptushonige (Nr. 53, 54) und drei aus Mischtracht stammende Honige (Nr. 30, 32, 49).

Unter den weich durchkristallisierten Honigen fanden sich mehrere, die hochviskos waren. Die feinen Zuckerkristalle waren hier gleichmässig in der flüssigen Honiglösung verteilt. Vollständig hart durchkristallisierte Honige fanden sich keine unter den geprüften Proben.

\section{Farbe}

Die Honigfarbe wird vorwiegend durch die Trachtquelle beeinflusst. Unter den geprüften Proben fallen durch ihre sehr helle Farbe gewisse Blütenhonige auf (z. B. Raps-, Weissklee-, Alpenrosen-, Orangen-, Rosmarinhonige).

Dunkel waren die beiden Heidehonige (Nr. 1, 2), der australische Eucalyptushonig (Nr. 12), ein tessiner Kastanienhonig (Nr. 3) und der Zuckerrohr- 
honig (Nr. 17). Dunkel bis fast schwarz sind die Honigtau-Honige und die Mischhonige mit starkem Honigtau-Anteil (Nr. 37, 38, 42, 44, 45, 46, 47, 48, $52)$.

\section{Wassergehalt}

Der Wassergehalt der untersuchten Honige bewegte sich zwischen 14,4 und 19,4\%. Er überstieg in keiner der Proben die von der schweizerischen Verordnung vorgeschriebene obere Grenze von $20 \%$. Nur in drei Proben (2, 27, 51) lag er knapp über $19 \%$. Eine dieser Proben ist ein Heidehonig bei dem nach der deutschen Honigverordnung und dem Codex alimentarius der Wassergehalt bis $23 \%$ betragen darf.

In dieser Hinsicht unterscheiden sich die geprüften Handelshonige aus der Schweiz von den in Deutschland und Frankreich untersuchten, deren Wassergehalt oft über $19 \%$, und zum Teil über $20 \%$ lag (Dustmann 1967, Borneck, Louis und Louveaux 1958).

$$
p H \cdot \text { Wert }
$$

Im allgemeinen besitzen Waldhonige höhere pH-Werte als Blütenhonige, was auf den höheren Aschengehalt des Honigtaus zurückzuführen ist, der die Säure abpuffert. Die pH-Werte der untersuchten Honige schwanken in weiten Grenzen (3,70-6,05). Am höchsten waren sie bei den aus einseitiger oder teilweiser Waldtracht stammenden Honigen der Gruppen 3 und 4, den beiden Heidehonigen (Nr. 1, 2) und dem Edelkastanienhonig (Nr. 3).

\section{Säure}

Je nach Art der Trachtquelle schwankt der Säuregehalt des Honigs innerhalb weiter Grenzen; bei den untersuchten Honigen zwischen 0,02 und $0,21 \%$ berechnet als Apfelsäure. Diese Befunde decken sich mit denen aus früheren Untersuchungen (Hadorn und Zürcher 1963). White und Mitarbeiter (1962) untersuchten 505 nordamerikanische Honigproben, deren Säuregehalt. (umgerechnet auf Apfelsäure) zwischen 0,03 und 0,32\% schwankte.

Auffallend niedrige Säuregehalte fanden sich im Kastanienhonig (Nr. 3), dem Cruciferenhonig (Nr. 8) und dem Robinienhonig (Nr. 19). Hohe Säuregehalte zeigten der Heidehonig ( $\mathrm{Nr} .1$ ), die Waldhonige $(\mathrm{Nr}, 39$ und 40) und die Mischhonige aus Blüten- und Waldtracht (Nr. 42 und 48).

\section{Hydroxymethylfurfural (HMF)}

Frisch geerntete, aus gemässigtem Klima stammende Honige enthalten kein oder nur Spuren von HMF (meistens unter $0,3 \mathrm{mg} \%$ ). Während der 
Lagerung bildet sich durch Wasserabspaltung aus Zucker, unter dem Ein fluss von Säure, je nach pH und Temperatur verschieden schnell HMF. Duisberg und Hadorn (1966) geben eine statistische Verteilung des HMF-Gehaltes von über 1500 Handelshonigen. Bei der grossen Mehrzahl lag der HMFGehalt unter $3,0 \mathrm{mg} \%$. Zu ähnlichen Ergebnissen kam Vorwohl (1969). Vor allem beim Umschmelzen des Honigs und bei Lagerung in der Wärme steigt der HMF-Gehalt rascher an (Hadorn und Mitarbeiter 1962, Hadorn und Zürcher 1973 a).

Nach dem Schweizerischen Lebensmittelbuch (1967) sind Werte über $3 \mathrm{mg} \%$ qualitätsmindernd, da sie auf eine Wärmeschädigung oder extrem lange Lagerung hindeuten. Für Handelshonige in Kleinverkaufspackungen werden, ähnlich wie in den Normen des Codex alimentarius, HMF-Gehalte, bis $4 \mathrm{mg} \% \mathrm{~g}$ toleriert.

Die Mehrzahl der untersuchten Honige besass niedrige HMF-Gehalte :

\begin{tabular}{|c|c|c|c|}
\hline 0,1 & $-1 \mathrm{mg} \%$ & 24 & coben \\
\hline 1 & -2 (C) & 19 & (c \\
\hline 2 & -3 & 6 & (c \\
\hline 3 & -4 & 1 & (c) \\
\hline über & 4 & 4 & (c \\
\hline
\end{tabular}

In 50 Proben blieb demnach der HMF-Gehalt unter der Grenze von $4 \mathrm{mg} \%$, in 2 weiteren lag er knapp darüber ( $\mathrm{Nr} .1$ und 18 mit 4,2 mg \%). Nur 2 Proben zeigen auffallend hohe HMF-Werte (Nr. 30 und 49 mit 11,3, bzw. $7,3 \mathrm{mg} \%$ ) und müssen als wärmegeschädigt betrachtet werden, besonders da auch die Enzyme teilweise inaktiviert sind.

Bei der Mehrzahl der Proben könnte demnach auf Grund des HMFGehaltes eine schonende Behandlung des Honigs angenommen werden; die Untersuchung der Enzymaktivität zeigte jedoch, dass das nicht immer zutraf.

\section{Enzyme}

Bienenhonig enthält mehrere Enzyme, die zum Teil aus den Rohstoffen (Nektar, Honigtau) stammen, zum grössten Teil aber während der Honigbereitung mit den Drüsensekreten der Bienen hineingelangen. Erfahrungsgemäss schwankt die Enzymaktivität in frischen, nicht erwärmten Honigen in weiten Grenzen. Nach dem Schweizerischen Lebensmittelbuch (1967) beträgt in normalen Honigen die Saccharasezahl 9-25, die Diastasezahl 13-40. Der Codex alimentarius sieht als unteren Grenzwert die Diastasezahl 8 vor (für von Natur aus enzymschwache Honigsorten die Diastasezahl 3). Einzelne, aus einseitiger Tracht stammende Honige, z. B. Orangen-, Robinien-, Gamander-, Lavandinund gewisse Eucalyptushonige, haben erfahrungsgemäss auffallend niedrige 
Enzymaktivitäten (Saccharasezahl 1-8, Diastasezahl 8-12). Als besonders enzymreich haben sich Edelkastanien-, Heide- und einseitige Waldhonige erwiesen. Trotz diesen grossen Schwankungen lassen sich aus den gefundenen Enzymaktivitäten Rückschlüsse auf eventuelle Wärmeschädigungen ziehen, besonders, wenn auch die entsprechenden HMF-Werte zur Beurteilung beigezogen werden. Beide Enzyme können durch Wärmeeinwirkung inaktiviert werden, wobei Saccharase bedeutend wärmeempfindlicher ist als Diastase (Codex alimentarius 1969, Duisberg 1975, Dustmann 1967, Hadorn 1964, Hadorn und Zürcher 1973 b, Schweiz. Lebensmittelbuch 1967, Vorwohl 1975).

Durch die unterschiedliche Wärmeempfindlichkeit der beiden Enzyme verschiebt sich das Verhältnis SaZ/DZ. Kiermeier und Köberlein (1954) haben vorgeschlagen, zur Beurteilung der Enzymaktivität das Verhältnis der beiden Enzyme he ranzuziehen, das als Kiermeier-Quotient bezeichnet wird $\left(\mathrm{K}-\mathrm{Q}=\begin{array}{c}\mathrm{SaZ} \\ \mathrm{DZ}\end{array}\right)$. Bei nicht erhitztem, frischem Honig schwankt diese Zahl zwischen 0,52 und 1,4 ; der Mittelwert beträgt 0,9 . Kiermeier-Quotienten unter 0,4 deuten in der Regel auf eine Wärmeschädigung hin.

Bei den untersuchten Honigen handelt es sich fast ausnahmslos um wiedererwärmte oder zur Abfüllung in Gläser verflüssigte Handelshonige. Eine grössere Anzahl davon hat extrem niedrige Saccharasezahlen, bei mehreren ist auch die Diastaseaktivität geschwächt. So liegt die Saccharasezahl in 9 Proben unter 2,0, bei ebenfalls niedrigen Diastasezahlen von 3,8-7,9 (Nr. 2, 18, 19, 21, $22,26,27,30,49)$.

Der Kiermeier-Quotient ist in diesen Proben extrem niedrig (0,01-0,14). Diese Honige sind zweifellos überhitzt worden, trotzdem der HMF-Gehalt nur in zwei davon deutlich zu hoch ist (Nr. 30, 49). In 11 weiteren Proben ist die Saccharaseaktivität gering $(\mathrm{SaZ}=2-4)$, die Diastaseaktivität aber zum Teil noch erhalten (Nr. 1, 4, 9, 10, 13, 14, 23, 28, 32, 53, 57). Von diesen enzymschwachen Honigen stammen 3 aus Robinien-, 2 aus Eucalyptusund einer aus Citrustracht, was die Enzymaktivität beeinflussen konnte. Allerdings befinden sich darunter auch die beiden Heidehonige, die von Natur aus eine hohe Enzymaktivität besitzen sollten. Auch der sehr niedrige Kiermeier-Quotient $(0,06$ und 0,14$)$ weist darauf hin, dass die Enzyme dieser Honige durch Wärme geschädigt waren.

Auffallend ist auch der aus einseitiger Eucalyptustracht stammende Honig aus Madagaskar (Nr. 11), der eine extrem niedrige Diastasezahl und eine etwas höhere Saccharasezahl hat $(\mathrm{DZ}=2,8, \mathrm{SaZ}=6,2)$, bei einem normalen HMF-Gehalt $(1,26 \mathrm{mg} \%)$. In einer Wiederholung der Bestimmungen nach 10 Monaten, bei Lagerung in Zimmertemperatur, ergaben sich ähnliche Zahlen ( $\mathrm{DZ}=2,9, \mathrm{SaZ}=5,1)$, wobei infolge der langen Lagerung nur die Saccharasezahl etwas abgenommen hatte. Dieser Befund bestätigt die bishe- 
rigen Beobachtungen, wonach gewisse Eucalyptushonige von Natur aus enzymarm sind (Duisberg 1975).

Abgesehen von den wenigen Fällen, in welchen die schwache Enzymaktivität möglicherweise durch die Rohstoffe beein flusst war, dürften die niedrigen Saccharase- und Diastasezahlen der untersuchten Honige auf Wärmeoder Lagerschädigungen zurückzuführen sein.

\section{Zuckerspektrum}

Frisch aus der Blüte gewonnener Nektar enthält in der Regel nur die drei Hauptzucker Fruktose, Glukose und Saccharose (Maurizio 1959, dort weitere Literatur). Einzelne Nektararten enthalten praktisch nur Saccharose (Rhododendron ferrugineum, Aesculus hippocastanum), andere hauptsächlich Hexosen und nur geringe Mengen Saccharose (Brassica napus, Pyrus communis, Rubus idaeus, Heracleum sphondylium). Das Verhältnis Fruktose zu Glukose schwankt in weiten Grenzen, in der Regel ist mehr Fruktose als Glukose vorhanden. Während der Honigbereitung und -Reifung wird die im Nektar enthaltene Saccharose unter der Wirkung der Bienenenzyme in Glukose und Fruktose gespalten. Gleichziteig bilden sich beträchtliche Mengen Maltose und eine Reihe höhermolekularer Oligosaccharide.

Das Zuckerspektrum des Honigs wird weitgehend durch die Wirkung der Bienenenzyme geprägt. Nur in seltenen Fällen, vor allem bei Sortenhonigen aus einseitiger Tracht, lässt sich der Ein fluss des Nektar-Zuckerbildes noch erkennen. Dieses verrät sich hauptsächlich im gegenseitigen Verhältnis der Hexosen. In Honigtauhonigen macht sich der Einfluss des Rohstoffes im Gehalt an Melezitose und Oligosacchariden bemerkbar (Maurizio 1959, 1964, 1965 a, dort weitere Literatur).

\section{Fruktose und Glukose}

Mengenmässig vorherrschend sind im Honig die Monosaccharide Fruktose und Glukose, deren Summe, als “ Invertzucker » bezeichnet, 50-80\% der Trockensubstanz des Honigs ausmacht. Der Invertzuckergehalt ist in Blütenhonigen höher $(70-80 \%)$ als in Waldhonigen (50-65\%). Im allgemeinen enthält der Honig mehr Fruktose (34-41\%) als Glukose (28-35 \%), das Verhältnis der beiden Zucker wird von der Herkunft der Rohstoffe beein flusst (Duisberg 1967, 1975, White u. Mitarb. 1962).

Die Mehrzahl der untersuchten Honige enthält mehr Fruktose als Glukose $(\mathrm{Fr} / \mathrm{Gl}=1,0-1,3$, s. Tabelle 4 letzte Rubrik). Einige der Proben sind wesentlich fruktosereicher $(\mathrm{Fr} / \mathrm{Gl}=1,4-1,66)$, z. B. die Heidehonige $(\mathrm{Nr} .1,2)$, der Edelkastanienhonig (Nr. 3) und der Robinienhonig (Nr. 19). In einzelnen 
Proben ist der Glukosegehalt höher als der Fruktosegehalt $(\mathbf{F r} / \mathbf{G l}=0,93-0,97)$, z. B. in den einseitigen Cruciferenhonigen (Nr. 6, 8 und 9).

\section{Saccharose}

Die europäischen Honigverordnungen setzen den zugelassenen Saccharosegehalt auf $5 \%$ für Blüten- und $10 \%$ für Waldhonige fest. Unter der Bezeichnung (Saccharose ) ist dabei der heute als " scheinbare Saccharose » umschriebene Begriff zu verstehen, wobei die Zunahme des Reduktionsvermögens durch schwache Hydrolyse bestimmt und als Saccharose berechnet wird (s. Schweiz. Lebensmittelbuch 1967). Bei schwacher Hydrolyse werden ausser Saccharose noch andere Di- und Oligosaccharide teilweise gespalten, wodurch zu hohe c Saccharosegehalte ) vorgetäuscht werden.

In Tabelle 4 sind die wahren Saccharosegehalte, die sich aus der gaschromatographischen Zuckerverteilung berechnen lassen, angegeben. Diese Werte sind fast ausnahmslos niedrig.

In 45 Proben blieb der Saccharosegehalt unter $1 \%$ in 40 davon betrug er $0-0,5 \%$. Von den 9 Proben mit einem über $1 \%$ liegenden Saccharosegehalt stammen 2 aus Robinientracht (Nr. 18 und 19, 2,9 bzw. 1,5\%) und eine weitere aus Robinienmischtracht ( $\mathrm{Nr} .28,1,9 \%$ ). Bei diesen Proben kann der höhere Saccharosegehalt mit der Trachtquelle verbunden sein. Robinienhonige sind für ihren verhältnismässig hohen Saccharosegehalt bekannt, was in den Normen des Codex alimentarius berücksichtigt wird.

Die Honige waren zur Zeit der Analysen ausnahmslos mehrere Monate, zum Teil mehr als ein Jahr alt. So hatten die Honigenzyme Zeit die Saccharose weitgehend abzubauen. Auffallend ist, dass mehrere der Proben mit etwas erhöhtem Saccharosegehalt $(1,0-2,9 \%)$ sehr geringe Saccharaseaktivitäten besitzen. Möglicherweise wurde in diesen Honigen die Saccharase, durch Wärembehandlung (Pasteurisation) bald nach der Ernte, weitgehend inaktiviert.

\section{Maltose und andere Disaccharide}

Aus neueren Untersuchungen ist bekannt, dass Honig neben Saccharose, weitere Disaccharide enthält, darunter regelmässig grössere Mengen Maltose. Als weitere Honig-Disaccharide werden genannt : Isomaltose, Maltulose, Turanose, Trehalose und Nigerose (Duisberg 1967, 1974, Siddiqui und Furgala 1967, White und Hoban 1959, White und Maher 1954 a, b, White u. Mitarb. 1962, dort weitere Literatur). Diese Disaccharide stammen zum. Teil aus den Rohstoffen (Honigtau), zum grössten Teil werden sie während der Honigreifung unter der Wirkung der Bienenenzyme neu gebildet (Maurizio 1965 $\mathbf{a}, \mathbf{b})$. 
Die untersuchten Honige enthielten durchwegs beträchtliche Mengen Maltose $(5,7-18,7 \%$, s. Tab. 4). Als besonders reich and Maltose erwiesen sich die einseitigen Waldhonige ( $\mathrm{Nr} .37,38,39$ - 12,7-14,2\%), mehrere WaldMischhonige (Nr. 42, 45, 46 - 11,0-18,7\%), 3 Edelkastanienhonige mit Honigtaueinschlag (Nr. 44, 47, $48-11,1-13,3 \%$ ) und ein Kastanien-Blütenhonig (Nr. $3-13,3 \%$ ). Auch die beiden Palmenhonige (Nr. 16, $17-11,0$ und 13,7\%) und die beiden Berghonige aus Alpenrosen-Mischtracht (Nr. 24, 25 - 11,0, $15,1 \%$ ) gehören zu den maltosereichen Proben.

Der Anteil der übrigen Disaccharide - in Tabelle 4 mit $\mathrm{X}_{1}, \mathrm{X}_{2}, \mathrm{X}_{3}$ bezeichnet - blieb gering $(0-2 \%)$. Diese Zuckerarten wurden nicht näher identifiziert, es können sich darunter Isomaltose und Nigerose befinden. Der Peak der Trehalose befindet sich in unseren Gaschromatogrammen an der gleichen Stelle wie derjenige der $\beta$-Maltose und lässt sich daher nicht erkennen. Melibiose, die Pourtallier (1968) im Gaschromatogramm eines Kiefern-HonigtauHonigs angeschrieben hatte, fanden wir in keinem der untersuchten Honige. In den Gaschromatogrammen der meisten Honige findet sich zwar regelmässig ein Peak an der Stelle der 3 -Melibiose (in Tabelle 4 mit ( $M$ ) bezeichnet). Da jedoch der Peak der $\alpha$-Melibiose, der unmittelbar davor erscheinen sollte, stets fehlt, dürfte bewiesen sein, dass die von uns untersuchten Honige keine nachweisbaren Mengen Melibiose enthalten und der mit “ $M$ » bezeichnete Peak einem anderen Disaccharid mit gleicher Retentionszeit wie 3-Melibiose entspricht.

\section{Trisaccharide}

Aus der Literatur ist bekannt, dass der Honig mehrere Trisaccharide und eine Reihe höhermolekularer Oligosaccharide enthält (BernardiniBattaglini und Bosi 1972, Goldschmidt und Burkert 1955, Maurizio 1965 a, b, White 1957, White und Maher 1953, 1954 a, White und Mitarb. 1962. dort weitere Literatur). Aehnlich wie die Disaccharide stammen auch die Tri- und Oligosaccharide zum Teil aus den Rohstoffen (besonders aus dem Honigtau), zum Teil bilden sie sich neu während der Honigbereitung und -Reifung. Unter den Trisacchariden sind vor allem zu nennen : Melezitose, Erlose ( $=\alpha$ Maltosyl- 3-D-fructofuranoside $=$ Fruktomaltose) und Raffinose.

In den Gaschromatogrammen der untersuchten Honige wurden Melezitose und Raffinose sauber erfasst. Andere Tri- und Oligosaccharide liessen sich mit unserer Methode nicht mit genügender Sicherheit nachweisen, da die Peaks mit sehr langer Retentionszeit sehr flach sind.

Melezitose fand sich in den untersuchten Honigen in Mengen von 1$12,6 \%$ (Tab. 4). Die Befunde beschränken sich auf Honige, die vorwiegend oder teilweise aus Honigtautracht stammen. In einzelnen Fällen macht sich schon ein sehr niedriger Honigtauanteil in geringen Melezitosebefunden 
bemerkbar (z. B. Nr. 49, 53). Den höchsten Melezitosegehalt hat, mit 12,6\%, der Schweizer-Waldhonig Nr. 36. Keine Melezitose enthält dagegen, trotz einem mittelstarken Honigtauanteil die Probe Nr. 43.

Der unterschiedliche Melezitosegehalt von Waldhonigen und Mischhonigen aus Wald- und Blütentracht erklärt sich aus der Tatsache, dass nicht alle Pflanzensauger melezitosehaltigen Honigtau absondern. So wird, je nach der Herkunft des Rohstoffes, melezitosereicher oder melezitosearmer Waldhonig geerntet. $\mathrm{Zu}$ den melezitosereichen gehören die aus einseitiger Honigtautracht von Lärchen, Linden und Fichten stammenden Honige, während Weisstannenhonige oft keine oder nur geringe Mengen Melezitose enthalten (Maurizio 1965 b, dort Literatur-Zusammenstellung).

Neuerdings wird in der Literatur erwähnt, dass Robinienhonig zu den melezitosereichen Honigsorten gehört (Bernardini-Battaglini und Bosi 1972). In unserer Untersuchung fand sich Melezitose weder in den beiden Robiniensortenhonigen ( $\mathrm{Nr} .18,19)$, noch in den beiden aus teilweiser Robinientracht stammenden Proben $(28,29)$ oder einem der übrigen reinen Blütenhonige (Gruppe 1, Tab. 3, 4). Da Robinienhonige als reich an Erlose bekannt sind (Pourtallier 1973, Pourtallier und Talliercio 1970) wäre es möglich, dass bei den erwähnten Melezitosebefunden in Robinienhonigen eine Verwechslung der Zuckerpeaks bei der Auswertung der Chromatogramme vorliegen könnte.

Weniger eindeutig mit dem Honigtauanteil verbunden sind in den untersuchten Honigen die Befunde von Raffinose. Die höchsten Raffinosemengen $(0,9-2,1 \%)$ fanden sich zwar ebenfalls in den einseitigen Waldhonigen und den Wald-Blütenmischhonigen (Nr. 37, 38, 39, 40, 41, 44, 48), aber auch ein Robinien-, ein Kastanien- und ein Blütenmischhonig (Nr. 3, 19, 29) enthielten Raffinose in Mengen von 0,5-1,5\% .

Das Vorkommen von Raffinose in Honig und seinen Rohstoffen ist öfters beschrieben, diskutiert und angezweifelt worden (Bernardini-Battaglini und Bosi 1972, Beutler 1953, Goldschmidt und Burkert 1955, Geissler und Steche 1962, Pourtallier 1968, Siddiqui und Furgala 1968, dort weitere Literatur). Siddiqui und Furgala weisen z. B. auf die Möglichkeit einer Verwechslung von Raffinose- und Theandrose-Befunden bei der Auswertung von Chromatogrammen hin. Ferner wird die Tatsache erwähnt, dass es, selbst nach Säurehydrolyse nie gelungen ist, im Honig Galaktose, einen Baustein der Raffinose nachzuweisen. Bei starker Säurehydrolyse wird Raffinose in Galaktose, Fruktose und Glukose gespalten. Bei schwacher Hydrolyse wird aus dem Trisaccharid Raffinose nur die Fruktose abgespalten und es entsteht das Disaccharid Melibiose.

Um zur Abklärung dieser Frage beizutragen, haben wir Versuche mit dem Waldhonig Nr. 38 unternommen, der 2,1\% Raffinose enthält. Nach starker Hydrolyse dieses Honigs war im Gaschromatogramm der Raffinose-Peak 
verschwunden, Galaktose liess sich jedoch nicht nachweisen. Selbst nach einem Zusatz von $2 \%$ Raffinose zum Honig fanden wir nach der starken Hydrolyse keine Spur Galaktose. Unter diesen Hydrolysebedingungen wird zwar die Raffinose vollständig gespalten, die dabei entstandene Galaktose jedoch zerstört, so dass man auf Abwesenheit von Raffinose schliessen könnte. Nach schwacher Hydrolyse des Honigs Nr. 38 war im Gaschromatogramm der Raffinose-Peak verschwunden, dafür erschienen die beiden deutlich ausgeprägten Peaks der $\alpha$-und der $\beta$-Melibiose. Damit dürfte das Vorkommen von Raffinose in gewissen Honigen klar bewiesen sein.

Eingegangen im Mai 1974

Reçu pour publication en mai 1974.

Adressen der Autoren :

Dr. H. HAdorn und K. ZürchER, Zentrallaboratorium COOP Schweiz, 4002 Basel, Schweiz. Dr. A. Maurizio, Rosenweg 9, 3097 Liebefeld, Schweiz.

\section{VERDANKUNG}

Fräulein Odette Rychen bestimmte die physikalischen Daten, die chemischen Gehaltszahlen und die Enzymaktivitäten. Mit der gaschromatographischen Untersuchung der Zucker befasste sich Herr Charles Strack. Für die sorgfältige Arbeit möchten wir beiden Mitarbeitern danken.

Frau Olga Rochat-Péclard besorgte in freundlicher Weise die Französisch-Uebersetzung der Zusammenfassung, wofür wir ihr zu bestem Dank verp flichtet sind.

\section{RÉSUMÉ}

ANALYSES DE MiELS COMMERCIAUX CONSIDÉRANT SPÉCIALEMENT LE SPECTRE DES SUCRES

\section{Introduction}

Ce travail comprend l'analyse physique, chimique et microscopique de 54 miels du commerce mis en vente en Suisse. Son intérêt principal est l'analyse chromatographique en phase gazeuse des espèces de sucre et les rapports entre le spectre de sucres et le spectre pollinique des miels analysés. La couleur, la consistance (forme de cristallisation), le $\mathrm{pH}$, le degré d'acidité, la teneur en eau et en HMF et l'activité diastatique (indice de saccharase et indice d'amylase) furent aussi déterminés. L'analyse devait aussi contribuer à juger la qualité des miels offerts sur le marché suisse.

\section{Méthodes}

La couleur des miels a été déterminée à vue et annotée avec les symboles correspondants à l'aide de l'atlas des couleurs, d'après le système Munsell (tableau 2). L'échelle de White élargie a été employée pour la description de la cristallisation (tableau 1). La teneur en eau, le $\mathrm{pH}$, le degré d'acidité, la teneur en HMF et l'activité diastatique ont été déterminés par les 
méthodes décrites dans le Manuel suisse des denrées alimentaires (1967) et celles de Hadorn et Zürcher $(1963,1966,1972)$. L'analyse microscopique se conforma au mode opératoire publié par la Commission internationale de Botanique apicole (1970). Une nouvelle méthode a été développée pour la détermination chromatographique en phase gazeuse des sucres (Hadorn, Zürcher et Strack 1974).

\section{Résultats}

Les résultats de l'analyse sont groupés dans les tableaux 3 et 4, répartis d'après le spectre pollinique en 4 groupes : miels de fleurs uni floraux, miels de fleurs mélangés, miels de miellat, miels de fleurs mélangés de miels de miellat.

1. D'après l'analyse microscopique les prescriptions de l'ordonnance sur les denrées alimentaires sont en général respectées dans la déclaration d'origine des miels examinés. Un seul échantillon de miel déclaré suisse contenait une petite proportion de miel étranger. La désignation des sortes de miel est moins convaincante, des considérations commerciales jouant souvent un trop grand rôle, surtout dans les miels peu appréciés des consommateurs.

2. Cristallisation. Il y avait parmi les miels analysés deux miels thixotropes de bruyère. Huit miels étaient coulants, beaucoup partiellement coulants et 32 miels complètement cristallisés (mous). Il n'y avait aucun miel fermement cristallisé.

3. La couleur des miels variait de très clair à presque noir, ce qui permit de constater les. rapports entre l'origine botanique et la couleur.

4. La teneur en eau des miels examinés varie entre 14,4 et $19,4 \%$ et correspond ainsi aux prescriptions de l'ordonnance suisse sur les denrées alimentaires.

5. Le $p H$ des échantillons se situe entre 3,70 et 6,05 , les chiffres les plus élevés concernent les miels de miellat et de bruyère.

6. La teneur en $H M F$ est, avec $0,1-4,0 \mathrm{mg} \%$, pour 50 des échantillons analysés, dans les limites prévues par le Manuel suisse des denrées alimentaires. Dans 2 échantillons il dépasse légèrement $4 \mathrm{mg} \% ; 2$ échantillons seulement avaient trop de HMF $(7,3$ et $11,3 \mathrm{mg} \%)$ et doivent être considérés comme altérés par la chaleur.

7. L'activité diastatique peut être désignée comme correspondant aux normes du Manuel suisse des denrées alimentaires ( $\mathrm{SaZ}=8,0-25,0 ; \mathrm{DZ}=8,0-29,7)$ dans la majorité des miels examinés, dans une partie de ceux-ci elle est affaiblie. Ainsi 9 échantillons ont un indice de saccharase au-dessous de 2,0 avec un indice d'amylase très bas aussi (3,8-7,9); dans 11 autres miels l'activité de saccharase est affaiblie, par contre l'activité de l'amylase est conservée. Quelques-uns de ces miels proviennent de récolte uniflorale sur le robinier, l'eucalyptus ou l'oranger, ce qui a pu influencer l'activité diastatique. Un échantillon a un indice d'amylase bas $(2,8)$ et un indice de saccharase plus élevé $(6,2)$, ce qui peut provenir d'une récolte monoflorale sur Eucalyptus. Mais pour la plupart des échantillons pauvres en diastases il faut envisager une manutention défectueuse, puisque les 4 échantillons à teneur en HMF plus ou moins élevée font partie du lot.

\section{Spectre de sucres}

Monosaccharides. La plupart des miels analysés contient un peu plus de fructose que de glucose $(\mathrm{Fr} / \mathrm{Gl}=1,0-1,3)$; dans quelques miels de bruyère, de châtaignier et de robinier, le fructose domine $(\mathrm{Fr} / \mathrm{GI}=1,4-1,66)$. Il y avait plus de glucose que de fructose dans des miels unifloraux de crucifères $(\mathrm{Fr} / \mathrm{Gl}=0,93-0,97)$.

Disaccharides. La teneur en saccharose des miels analysés est partout très basse, dans 45 échantillons elle est en dessous de $1 \%$. Sur les 9 échantillons contenant un peu plus de saccharose $(1,1-2,9 \%), 3$ proviennent de récolte totale ou partielle sur robinier. La teneur en maltose des échantillons est sensiblement plus élevée $(5,7-18,7 \%)$. Parmi les miels les plus riches en 
maltose, on trouve 3 miels de miellat, plusieurs miels de fleurs mélangés de miel de miellat, un miel de châtaignier, 2 miels de fleurs de montagne avec du rhododendron et 2 miels de palmier.

Il y avait dans les chromatogrammes, à part le saccharose et le maltose, 4 autres disaccharides, désignés par $X_{1}, X_{2}, X_{3}$ et $M$ (tableau 4), qui n'ont pas été identifiés plus à fond. Le disaccharide désigné par « $M$ » n'est pas identique au melibiose.

Trisaccharides. Dans les trisaccharides on a déterminé le mélézitose et le raffinose. Dans le domaine des tri- et oligosaccharides se trouvent aussi quelques faibles peaks non identifiés.

On trouve le mélézitose (1-12,6\%) seulement dans les échantillons provenant en plus ou moins grande proportion de miels de miellat. Un des miels de miellat, les deux miels purs de robinier et deux miels mélangés de robinier ne contiennent pas de mélézitose.

Le raffinose était en quantités variables dans un certain nombre des miels analysés $(0,9$ $2,1 \%$ ), mais sa relation avec la proportion de miellat dans le miel était moins probante qu'avec le mélézitose. Des essais d'hydrolyse furent entrepris pour étudier la présence de raffinose dans le miel qui prouvèrent que le Peak « raffinose » dans les chromatogrammes correspond vraiment à ce sucre.

\section{LITERATURVERZEICHNIS}

Battaglini M., Bosi G., 1973, Ricerche comparate sulla natura dei glucidi di alcuni mieli mono flora e dei rispettivi nettari. Simposio Intern. Apicoltura, Torino 1972, 123-129.

Bernardini-Battaglini M., Bosi G., 1972, Bestimmung der Kohlenhydrate durch Gaschromatographie und die Möglichkeiten ihrer Verwendung bei der Honigschätzung. Apiacta, VII, 5-8.

Beutler R., 1953, Nectar. Bee World, 34, 106-116, 128-136, 156-162.

Borneck R., Louis J., Louveaux J., 1958, Une enquête sur le marché du miel à Paris pendant l'hiver 1957-58. Ann. Abeille, 1, 223-245.

Codex alimentarius commission, 1969, Recommended European standard for honey. Joint FAO/WHO Food Standard Programme. Ref. No. CAC/RS 12-1969 FAO, Rome.

Duisberg H., 1967, Honig und Kunsthonig. Handbuch der Lebensmittelchemie, V, T. 1. 491559, Springer, Berlin-Heidelberg-New York.

Duisberg H., 1975, Physikalische und chemische Eigenschaften des Honigs. In Zander/ Maurizio, Der Honig, Ulmer, Stuttgart.

Duisberg H., Hadors H., 1966, Welche Anforderungen sind an Handelshonige zu stellen? Miti. Lebensm. unters. Hyg. Bern., 57, 386-407.

DustmanN J.-H., 1967, Messung von Wasserstoffperoxid und Enzymaktivität in mitteleuropäischen Honigen. Z. Bienenforsch. 9, 66-73.

Fellenberg Th.-v., 1946, Schweizerische Honigstatistik III. Honige aus den Jahren 19371940. Beih. Schweiz. Bienenztg., 1 (12), 571-873.

Focke E., 1969, Das Pollenbild chinesischer Honige. Z. Bienenforsch., 9, 196-206.

FockE E., 1973, Briefliche Mitteilung.

Geissler G., STECHE W., 1962, Natürliche Trachten als Ursache für Vergiftungserscheinungen bei Bienen und Hummeln. Z. Bienenforsch., 6, 77-92.

Goldschmidt St, BURKent H., 1955, Vorkommen einiger im Bienenhonig bisher unbekannter Zucker. Hoppe-Seylers. Z. Phys. Chem., 300, 188-200.

Hadorn H., 1964, Enthalten Orangenblüteı- und Lavendelblütenhonige enzymhemmende Stoffe? Ann. Abeille, 7, 311-320.

Hadorn H., Kovacs A.-S., 1960, Zur Untersuchung und Beurteilung von ausländischen Bienenhonigen auf Grund des Hydroxymethylfurfurol- und Diastasegehaltes. Mitt. Lebensm. unters. Hyg. Bern., 51, 373-390.

Hadorn H., Zürcher K., 1963, Formolzahl von Honig. Gleichzeitige Bestimmung von Formolzahl, pH, freier Säure und Lactongehalt in Honig. Mitt. Lebensm. unters. Hyg. Bern., 54, 304-321.

Hadorn H., Zürcher K., 1966, Eine verbesserte polarimetrische Methode zur Saccharasezahl-Bestimmung in Honig. Dtsch. Lebensmitt.-Rundschau, 62, 195-201.

HADORN H., ZürCHER K., 1973 a, Über Schädigungen des Honigs beim Verflüssigen im technischen Abfüllbetrieb. Dtsch. Lebensmitt.-Rundschau, 69, 273-276. 
HADORN H., ZürCHER K., 1973 b, Erfahrungen mit einer neuen kinetischen Methode zur Bestimmung der Diastasezahl in Honig und über Eigenschaften der Honigdiastase. Apidologie, 4, 65-80.

Hadorv H., Zürcher K., DoevelaAR F.-H., 1962, Über Wärme-und Lagerschädigungen von Bienenhonig. Mitt. Lebensmitt. unters. Hyg. Bern., 53, 191-326.

Hadorn H., Zürcher K., Strack Ch., 1974, Gaschromatographische Bestimmung der Zuckerarten in Honig. Mitt. Lebensmitt. unters. Hyg. Bern., 65, 198-208.

Internationale Kommission für Bienenbotanik I.U.B.S. (LouveauX/Maurizio/VorwoHL), 1970, Methodik der Melissopalynologie. Apidologie, 1, 193-209, 211-227.

Kiermeier F., Köberlein W., 1954, UUber Hitzeinaktivierung von Enzymen in Honig. $Z$. Lebensmitt. unters.-Forsch, 98, 329-347.

Louveaux J., 1974, Brie fliche Mitteilung.

Maurizio A., 1959, Papierchromatographische Untersuchungen an Blütenhonigen und Nektar. Ann. A beille, 2, 291-341.

Maurizio A., 1964, Das Zuckerbild blütenreiner Sortenhonige. Ann. Abeille, 7, 289-299.

Maurizio A., 1965 a, Honigentstehung-Honigreifung. Dt. Bienenwirtsch. 16, 233-240.

Maurizio A., 1965 b. Honigtau-Honigtauhonig. In Kloft/Maurizio/Kaeser, Das Waldhonigbuch, 159-185. Ehrenwirth München.

Munselt A., 1932, 1943, Book of Color. Munsell Color Co. Baltimore Md. Vol. I, II.

Pourtallier J., 1968, Úber die Benutzung der Gaschromatographie für die Bestimmung der Zucker im Honig. Z. Bienenforsch., 9, 217-221.

Pourtallier J., 1973, Caractérisation physico-chimique des miels. Simposio Intern. Apicoltura, Torino 1972, 91-95.

Pourtallier J., Taliercio Y., 1970, Les caractéristiques physico-chimiques des miels en fonction de leur origine florale. 1. Application à un projet de normes pour les grandes variétés de miels. Bull. Apic. Doc, sci. tech. Inf., 13, 58-68.

Schweizerisches Lebensmttelbugh 1967, 2, Kap. 23, 1-35. 5. Aufl. Eidg. Drucks. Materialzentr. Bern.

Sechrist E.-L., 1925, The color grading of honey. US-Dep. Agric. Circ., No. 364.

SidDIQUi I.-R., FURGALA B., 1967, Isolation and characterization of oligosaccharides from honey. I. Disaccharides. J. Apic. Res., 6, 139-145.

Siddiqui I.-R., Furgala B., 1968. Isolation and charascterization of oligosaccharides from honey. II. Trisaccharides. J. Apic. Res., 7, 51-59.

VorwoHL G., 1969, Der Hydroxymethylfurfurolgehalt in deutschen Honigen. Z. Bienenforsch., 9, 504-508.

VorwoHz G., 1975, Grundzüge der Honiguntersuchung und-Beurteilung. In Zander/Maurizio, Der Honig. Ulmer, Stuttgart.

WhiтE J.-W. 1957, The composition of honey. Bee World, 38, 57-66.

WhITE J.-W. HobAN N., 1959, The composition of honey. IV. Identification of the disaccharides. Arch. Biochem. Biophys., 80, 386-392.

White J.-W., MAher J., 1953, $\alpha$-Maltosyl- $\beta$-D-fructofuranoside, a trisaccharide enzymatically synthezised from sucrose. J. Amer. Chem. Soc. 75, 1259.

WhIte J.-W., MaHer J., 1954 a, Selective adsorption method for determination of the sugars of honey. J. Ass. off. agr. Chem., 37, 466-478.

White J.-W., MAher J., $1954 \mathrm{~b}$, Sugar analysis of honey by a selective adsorption method. J. Ass. off. agr. Chem., 37, 478-486.

White J.-W., Riethof M.-L., Subers M.-H., Kushnir J., 1962, Composition of American honeys. US-Dep. Agric. Techn. Bull. No. 1261.

WinkLer O., 1955, Beitrag zum Nachweis und zur Bestimmung von Oxymethylfurfurol im Honig. Z. Lebensmitt. unters. - Forschg., 102, 161-167.

Zürcher K., HadorN H., 1972, Eine einfache kinetische Methode zur Bestimmung der Diastasezahl in Honig. Dtsch. Lebensmitt. - Rundschau, 68, 209-216. 